\title{
MOWLAS: NIED observation network for earthquake, tsunami and volcano
}

\author{
Shin Aoi ${ }^{*}$, Y Youichi Asano, Takashi Kunugi, Takeshi Kimura, Kenji Uehira, Narumi Takahashi, Hideki Ueda, \\ Katsuhiko Shiomi, Takumi Matsumoto and Hiroyuki Fujiwara
}

\begin{abstract}
National Research Institute for Earth Science and Disaster Resilience (NIED) integrated the land observation networks established since the 1995 Kobe earthquake with the seafloor observation networks established since the 2011 Tohoku earthquake and tsunami as MOWLAS (Monitoring of Waves on Land and Seafloor) in November 2017. The purpose of MOWLAS is to provide comprehensive, accurate, and rapid observation and monitoring of earthquake, tsunami, and volcano events throughout Japan and its offshore areas. MOWLAS data are widely utilized for long-term earthquake forecasting, the monitoring of current seismic activity, seismic and tsunami hazard assessments, earthquake early warning, tsunami warning, and earthquake engineering, as well as earthquake science. Ocean bottom observations provide an extension of observations to areas where no people are living and have the advantage of increasing lead time of earthquake early warning and tsunami warning. The application of recent technology advancements to real-time observations as well as the processing of MOWLAS data has contributed to the direct disaster mitigation of ongoing earthquakes. These observations are fundamental for both science and disaster resilience, and thus it is necessary to continue ceaseless operation and maintenance.
\end{abstract}

Keywords: MOWLAS, Fundamental earthquake observation network, Hi-net, K-NET, KiK-net, F-net, V-net, S-net, DONET, Real-time observation

\section{Introduction}

Japan is an earthquake-prone country in which the importance of earthquake observations, both for research and disaster prevention, has been well recognized. Official earthquake observations in Japan first began in 1875 (Hamamatsu 1966) by Japan Meteorological Agency (JMA), which has conducted nationwide observations ever since. Other organizations including universities and research institutes mainly perform regional observations. National Research Institute for Earth Science and Disaster Resilience (NIED) has been conducting observations for nearly 50 years, including the Iwatsuki Crustal Activity Observatory which began operations in 1973 with a 3510-m deep borehole (Takahashi 1982), the Kanto and Tokai Crustal Activity Observation Network (Hamada

\footnotetext{
*Correspondence: aoi@bosai.go.jp

National Research Institute for Earth Science and Disaster Resilience, 3-1 Tennodai, Tsukuba, Ibaraki 305-0006, Japan
}

et al. 1982; Okada 1984), strong motion observation networks (Kinoshita 2003), and the Sagami-Bay Sea Bottom Earthquake Observatory (Eguchi et al. 1998). Prior to the 1995 Kobe earthquake, the primary focus of earthquake research was on short-term earthquake predictions, and observation resources were concentrated in designated regions that the Act on Special Measures for Large-Scale Earthquakes deems to be particularly important, such as the Tokai earthquake area. However, based on the lessons learned from that earthquake and the 2011 Tohoku earthquake and tsunami, the earthquake observation policies in Japan aimed at disaster prevention were modified drastically to perform uniformly spaced earthquake observations all over Japan on land, as well as earthquake and tsunami observations on seafloors, in acknowledgement that earthquakes could occur anywhere in the country at any time.

The 1995 Kobe earthquake, which caused more than 6400 fatalities, occurred outside the designated regions, 
where earthquake observations were insufficient, so it was difficult to capture the overall situation immediately after the event. In the aftermath of that disaster, the Act on Special Measures for Earthquake Disaster Countermeasures was enacted in June 1995, and the Headquarters for Earthquake Research Promotion (HERP) was established in July 1995 to promote the fundamental survey and observation for earthquake research as a governmental policy.

Regarding earthquake observations on land, NIED has overall responsibility for nationwide earthquake observations based on the fundamental earthquake survey and observation plans set forth by HERP in 1997 (The Headquarters for Earthquake Research Promotion 1997). These observation networks aim to promote earthquake mitigation and deepen our understanding of earthquake phenomena through long-term evaluations of earthquake occurrences, evaluations of current seismic activity, seismic and tsunami hazard assessments, and the rapid transmission of earthquake information for purposes such as early warning. The fundamental earthquake observation networks in Japan are High Sensitivity Seismograph Network Japan (Hi-net), which consists of about 800 stations to observe microearthquakes; Kyoshin Network (K-NET) and Kiban Kyoshin Network
(KiK-net), which are strong motion networks that operate about 1700 stations in total; and Full Range Seismograph Network of Japan (F-net), which is a broadband network consisting of 73 stations that can observe broadband seismic waves of up to several hundreds of seconds (Table 1, Fig. 1). Portions of these observation networks have been in operation since as early as 1996, and most stations began operations in the early 2000s as Okada et al. (2004) summarized for Hi-net, F-net, K-NET, and KiK-net. To facilitate crustal deformation observations, Geospatial Information Authority of Japan (GSI) has expanded the GNSS Earth Observation Network System (GEONET), which consists of about 1300 stations, to cover all of Japan (Sagiya 2004).

Regarding volcanic observations, NIED constructed and operates the Fundamental Volcano Observation Network (V-net), which consists of 55 stations at 16 volcanoes, to facilitate volcano research. There are a total of 111 active volcanoes in Japan. JMA currently monitors the 50 active volcanoes that have been designated by the Coordinating Committee for Prediction of Volcanic Eruption (CCPVE) as volcanoes that need enhanced monitoring for disaster prevention, which includes issuing warnings when volcanic activity increases. The 16 volcanoes observed by NIED are included in the 50

Table 1 Information on MOWLAS stations, including their numbers, sensors, URLs, and DOIs

\begin{tabular}{|c|c|c|c|c|}
\hline Name of network & \# of stn* & Sensors at typical station & URL & DOI \\
\hline MOWLAS & 2148 & & $\begin{array}{l}\text { https://www.mowlas.bosai.go.jp/ } \\
\text { mowlas/?LANG=en }\end{array}$ & https://doi.org/10.17598/nied.0009 \\
\hline Hi-net & 782 & Velocity seismometer, tiltmeter & $\begin{array}{l}\text { https://www.hinet.bosai.go. } \\
\text { jp/?LANG=en }\end{array}$ & https://doi.org/10.17598/nied.0003 \\
\hline K-NET & 1037 & Strong motion accelerometer & https://www.kyoshin.bosai.go. & https://doi.org/10.17598/nied.0004 \\
\hline KiK-net & $(695)^{* *}$ & $\begin{array}{l}\text { * Strong motion accelerometer (vertical } \\
\text { array) }\end{array}$ & jp/?LANG=en & \\
\hline F-net & 73 & $\begin{array}{l}\text { Broadband seismometer, velocity-type } \\
\text { strong motion seismograph }\end{array}$ & $\begin{array}{l}\text { https://www.fnet.bosai.go.jp/top. } \\
\text { php?LANG=en }\end{array}$ & https://doi.org/10.17598/nied.0005 \\
\hline V-net & 55 & $\begin{array}{l}\text { Velocity seismometer, broadband seis- } \\
\text { mometer, tiltmeter, GNSS }\end{array}$ & https://www.vnet.bosai.go.jp/ & https://doi.org/10.17598/nied.0006 \\
\hline S-net & 150 & $\begin{array}{l}\text { Accelerometer (analog/frequency), } \\
\text { velocity seismometer, pressure gauge }\end{array}$ & https://www.seafloor.bosai.go.jp/ & https://doi.org/10.17598/nied.0007 \\
\hline S1 & 22 & & & \\
\hline S2 & 26 & & & \\
\hline S3 & 26 & & & \\
\hline S4 & 28 & & & \\
\hline S5 & 23 & & & \\
\hline S6 & 25 & & & \\
\hline DONET & 51 & \multirow{3}{*}{$\begin{array}{l}\text { Strong motion accelerometer, broad- } \\
\text { band seismometer, pressure gauge, } \\
\text { differential pressure gauge, hydro- } \\
\text { phone, precise thermometer }\end{array}$} & & https://doi.org/10.17598/nied.0008 \\
\hline DONET1 & 22 & & & \\
\hline DONET2 & 29 & & & \\
\hline
\end{tabular}

* As of the end of 2019

** All the KiK-net stations share the station with Hi-net 


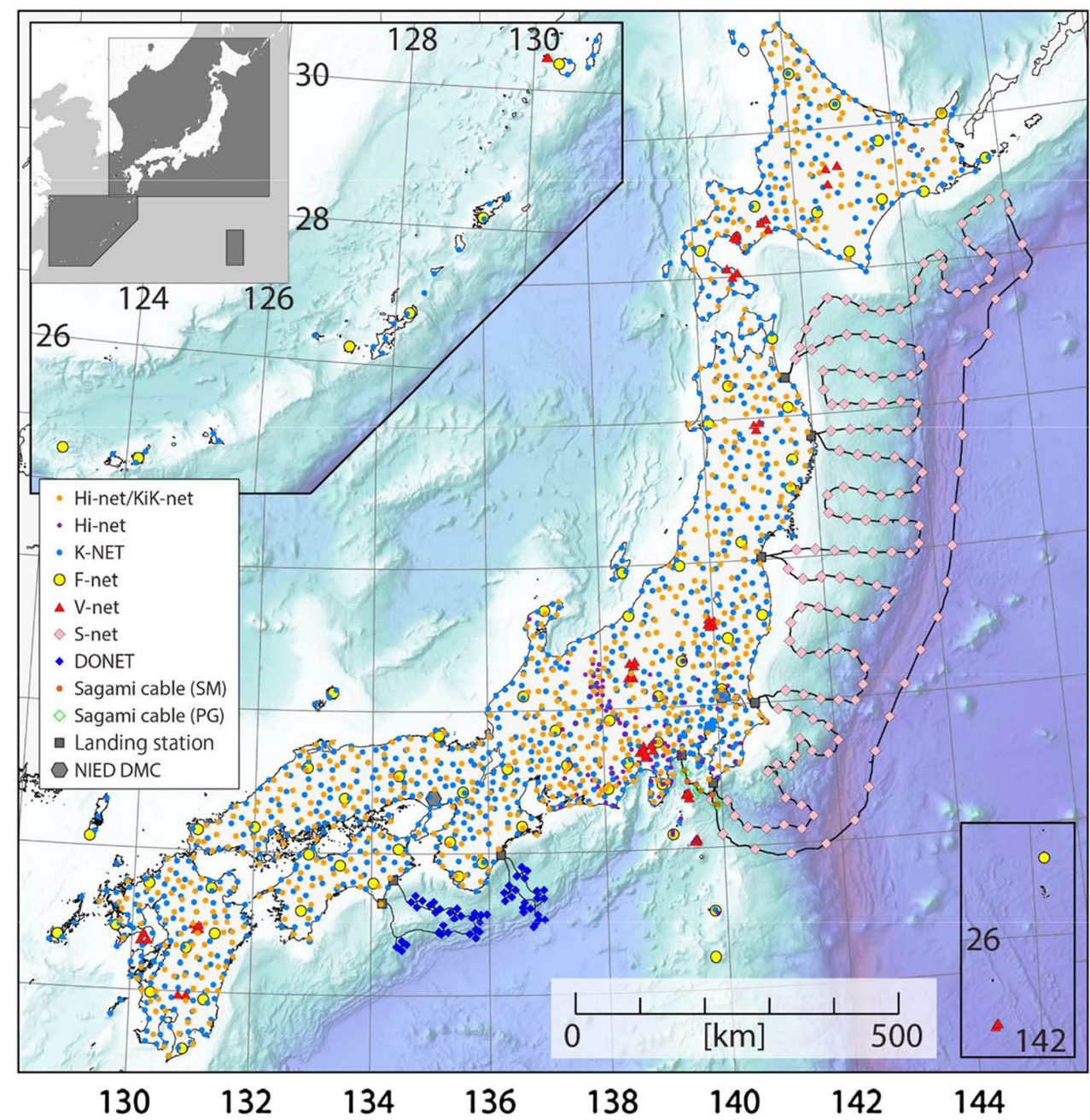

Fig. 1 MOWLAS station distribution for the three regions of the inset map. SM and PG indicate seismometers and pressure gauges, respectively

volcanoes, and the 15 of the 16 volcanoes excluding Ioto are included in the 25 volcanoes selected by the Committee on Earthquake and Volcano, Subdivision on Geodesy and Geophysics of the Council for Science and Technology of the Government of Japan for particularly extensive observation.

Regarding earthquake and tsunami seafloor observations, while dense networks of earthquake observation stations on land have expanded to cover all over Japan since the 1995 Kobe earthquake, there were only 45 stations in the sea at the time of the 2011 Tohoku earthquake and tsunami. The limited number of earthquake and tsunami observations along the Pacific offshore areas of eastern Japan resulted in magnitude underestimates, which caused underestimates in earthquake early warning and tsunami warning. Because it is now clear that near-field tsunami warnings that are based solely on seismometers deployed on land have essential limitations in terms of lead time and precision for tsunami height estimations, one of the most important lessons learned from the 2011 Tohoku earthquake and tsunami is that there was an insufficient number of offshore observation stations. At that time, cable-type seafloor observation systems for earthquakes and tsunamis had been installed offshore by JMA, one off Tokai in 1979, one off Boso Peninsula in 1985, and one off Tonankai in 2008. NIED installed systems off Sagami Bay in 1996, and Earthquake Research Institute of the University of Tokyo (ERI) installed systems off eastern Izu in 1994, off Sanriku in 1995, and off Awashima in 2010. Japan Agency for Marine-Earth Science and Technology (JAMSTEC) installed systems off Muroto Cape in 1997 and off Kushiro and off Tokachi in 1999. Unfortunately, although realtime observations using ocean bottom cable systems are effective for disaster information delivery immediately after the occurrence of earthquakes, the installed 
observation networks were insufficient in number and insufficiently uniform in terms of their spatial distribution. As a result, the construction of new seafloor observation networks was deemed to be an urgent matter.

Dense Oceanfloor Network system for Earthquakes and Tsunamis (DONET) is an ocean bottom observation network consisting of 51 stations that is focused on the monitoring of earthquakes and tsunamis along the Nankai Trough. These stations cover the eastern half of the Nankai area, one of the regions where the next megathrust earthquake is anticipated. At the time of the 2011 Tohoku earthquake and tsunami, DONET1 was under construction by JAMSTEC and ten stations were in operation (Kawaguchi et al. 2011). 20 stations of DONET1 were in operation in July 2011, and all 51 stations of DONET1 and DONET2 were completed in March 2016. Their ownership and operation were transferred to NIED in April 2016.

Taking into consideration the overall situation after the 2011 Tohoku earthquake and tsunami, the Japanese government decided to construct the Seafloor observation network for earthquakes and tsunamis along the Japan Trench (S-net) offshore of the Pacific coast of eastern Japan. NIED completed construction of S-net in March 2017, and began operating it for real-time direct measurements of earthquakes and tsunamis using ocean bottom observation networks. S-net currently consists of 150 observatories equipped with seismometers and pressure gauges linked together by ocean bottom fiber optic cables. S-net is expected to provide prompt and accurate earthquake and tsunami observation to increase lead time of warnings for offshore earthquakes, and to contribute to a deeper understanding of offshore earthquakes.

Seven nationwide observation networks were integrated into MOWLAS, which is operated by NIED, in November 2017. As shown in Table 1 and Fig. 1, MOWLAS now consists of four earthquake observation networks on land (Hinet, K-NET, KiK-net, and F-net), two seafloor earthquake and tsunami observation networks (S-net and DONET), and a volcano observation network (V-net). Earthquakes can occur beneath land or seafloor. For earthquakes that occur beneath seafloor, the released earthquake energy propagates toward land as seismic waves that can cause disasters. The need for separate land and seafloor observation systems is due to differences in the respective observation technologies. Integrating the analyses of land and seafloor observations provides a number of advantages. Therefore, it is vitally important to store all the observation data together, and to promote research and the utilization of the integrated data.

Most MOWLAS continuous observation data are transmitted by EarthLAN, which is a commercial service for earthquake observations developed by NIED and NTT
Communications Corporation (NTT-Com). EarthLAN, which is constructed on Internet Protocol/virtual private network (IP-VPN) technology, operates at a very low transmission latency of typically up to $0.5 \mathrm{~s}$, and is equipped with control center functions that monitor whether the data are transmitted correctly. All data are continuously recorded and directly transmitted from each station through EarthLAN to the NIED Data Management Center (DMC) in Tsukuba, Ibaraki Prefecture, and to JMA in both Tokyo and Osaka, where the data are utilized for earthquake early warning and tsunami warning. All of the data from the seismological observation networks operated by NIED, JMA, universities, and other institutes are exchanged in real-time through the Tokyo Data Exchange (TDX), which is a component of EarthLAN. As the national data center, NIED archives and provides the data upon request in digital form on the Internet, as well as through contributions to earthquake catalogs and focal mechanisms.

This paper introduces MOWLAS as of the end of 2019, which was installed and is operated by NIED, and explains how the network data contribute to discoveries in earth science and their social implementation.

\section{Earthquake observation networks on land Hi-net History of NIED borehole observations}

Hi-net is a nationwide high-sensitivity seismograph network in Japan that was constructed primarily after the 1995 Kobe earthquake (Fig. 1 and Additional file 1: Figure S1). The observation style and technology to install velocity meters and tiltmeters at the borehole bottoms were basically established by the 1980s. In 1970, National Research Center for Disaster Prevention (NRCDP), which was reorganized into NIED in 1990, started a deep borehole observation project to investigate crustal activity in and around the Tokyo Metropolitan Area as part of a national earthquake prediction project. This densely populated and extremely prosperous region sits atop sedimentary layers that are between 2000- and 4000-m-thick. Therefore, sensors need to be installed at the bottom of deep boreholes located at the pre-tertiary basement to obtain high-quality data with good signal-to-noise ratios $(\mathrm{S} / \mathrm{Ns})$. To conduct deep borehole observations at such depths, it was first necessary to develop instruments capable of operating in extremely high temperature and pressure environments. The development and installation process took about 10 years, and NRCDP began observations at three sites, Iwatsuki, Shimohsa, and Fuchu, with sensor depths of 3510, 2300, and $2750 \mathrm{~m}$, respectively, by 1981 (Takahashi 1982).

In addition to these deep borehole stations, a largescale network for microearthquake and ground tilt 
observations was constructed in the Kanto and Tokai areas including the Tokyo Metropolitan Area during the period from the late 1970s to the early 1980s (Fig. 2). Most of these stations are composed of mainly $100-\mathrm{m}$ boreholes enclosed in casing pipes with a diameter of 4 in. For this network, it was necessary to develop a small-sized, force-balanced pendulum tiltmeter. The measurement range of the tiltmeter is $\pm 2 \times 10^{-4}$ radians and the resolution is $6 \times 10^{-9}$ radians, and the long-term drift was found to be smaller than a few microradians per year in the half year of measurements taken after installation (Sato et al. 1980). 50 stations were constructed in the Kanto-Tokai area and have been operated along with the three deep borehole stations since 1983 (Hamada et al. 1982; Okada 1984). Additional 14 semi-deep borehole stations with sensor depths of 1000 to $2000 \mathrm{~m}$ and a deep borehole station, Koto, with a sensor depth of $3000 \mathrm{~m}$ were constructed in the 1990s (Okada et al. 2000). At the same time, an ocean bottom cable system was installed at six seismic and three pressure observation sites deployed as part of the Earthquake and Tsunami Monitoring Cable (ETMC) system in the Sagami Bay (Eguchi et al. 1998). Approximately 70 stations in operation to observe shallow microearthquakes in this area are collectively known as the Kanto and Tokai Crustal Activity Observation Network as shown in Fig. 2.

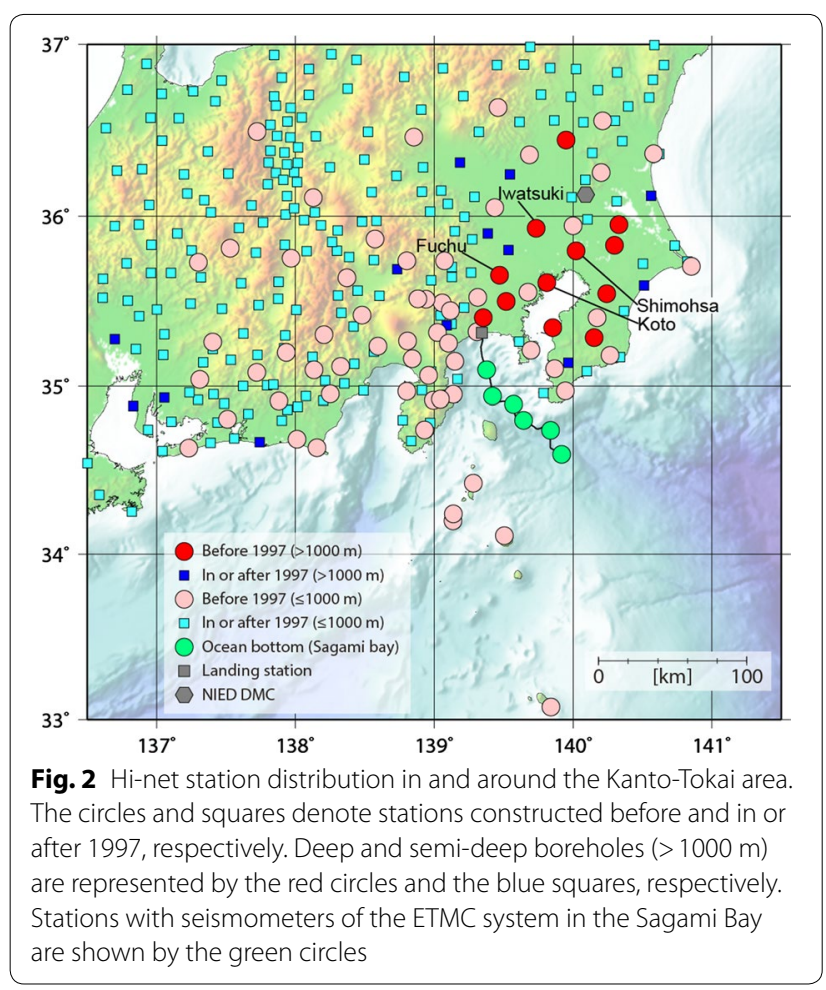

\section{Hi-net as fundamental observation}

After the 1995 Kobe earthquake, based on the HERP policy related to the fundamental survey and observation, Hi-net was established (Okada et al. 2004; Obara et al. 2005; Shiomi et al. 2009). The construction of this network was driven by the need to evaluate the largest possible earthquakes and the long-term occurrence potentials of earthquakes. For this purpose, we need to precisely evaluate the bottom of the seismogenic layer at depths of 10 to $20 \mathrm{~km}$ from hypocenters of shallow crustal earthquakes, because the largest possible crustal earthquakes are considered to be strongly related to the seismogenic layer thickness. To constrain the hypocentral depths to around 10 to $20 \mathrm{~km}$, the nearest epicentral distances from the observation stations are required to be within $20 \mathrm{~km}$; therefore, Hi-net station intervals were set to be approximately $20 \mathrm{~km}$. Furthermore, to acquire much data for the evaluation of the seismogenic layer thickness, it is necessary to observe quite weak signals from microearthquakes contaminated by various types of noise. Therefore, Hi-net seismometers were installed at depths of $100 \mathrm{~m}$ or more.

HERP set a policy stipulating that data from fundamental observations would be widely shared and used for both earthquake mitigation and deepening our understanding of earthquake phenomena. Based on this policy, data exchange among NIED, JMA, universities, and institutes was promoted. JMA began analyzing the combined data as a unified seismic catalog that is widely distributed, and NIED, in its role as the national data center responsible for archiving and distribution, began storing waveform data and continuously transmitting the data to JMA, as well as to universities and institutes. All other interested researchers can acquire continuous and/or event-triggered waveform data directly from the Hi-net website.

\section{Observation instruments}

The primary Hi-net sensor is a short-period velocity meter manufactured by Akashi Co., Ltd. (now Mitutoyo Corporation) which is a moving coil-type sensor with a natural frequency of $1 \mathrm{~Hz}$ and a flat sensitivity of approximately $200 \mathrm{~V} / \mathrm{m} / \mathrm{s}$ above this frequency. To ensure the quality of velocity meters, NIED routinely examines the test coil responses of these instruments everyday using an electrical calibration mechanism and monitors their natural frequencies and damping constants (Obara et al. 2005; Ueno et al. 2015). In addition to the installed shortperiod three-component velocity seismometers, Hi-net also includes two-component tiltmeters. Analog voltage signals from the three-component velocity seismometers and two-component tiltmeters are digitized by an analogto-digital (A/D) converter. This device has a resolution of 
27 bits for 20 or $100 \mathrm{~Hz}$ sampling and a dynamic range of $130 \mathrm{~dB}$ based on oversampling and decimation filtering (Obara et al. 2005; Shiomi et al. 2005). NIED has been developing the $\mathrm{Hi}$-net $\mathrm{A} / \mathrm{D}$ converters for the last two decades. The latest A/D converter, which is manufactured by Keisokugiken Corporation, contains an energyefficient decimation filter based on a field-programmable gate array (FPGA), and the A/D converter can continue operating for at least 3 days without an external power supply when a power outage. The A/D converter, batteries, and telephone-related equipment are installed in huts at each station.

\section{Integrated observation networks and data}

Borehole Hi-net stations, along with their huts, were constructed at approximately 700 sites during the period from 1997 to 2004. Most of these stations, which were constructed by NIED by 2000 , began providing data in October 2000. In addition, NIED constructed 15 stations with $50 \mathrm{~m}$ boreholes without huts for use in an integrated observation research project for the ItoigawaShizuoka Tectonic Line active fault system during the period from 2005 to 2010 (Asano et al. 2010). Later, these 15 stations were included in Hi-net. In 2006, the existing A/D converters and telemetry system of the Kanto-Tokai Crustal Activity Observation Network (Kanto-Tokai Network) were replaced with the same system as that used throughout Hi-net, and these stations of the Kanto-Tokai Network were incorporated into Hi-net. Almost all of the approximately 800 stations (Fig. 1 and Additional file 1: Figure S1) equipped with short-period velocity meters are operated integrally as $\mathrm{Hi}$-net.

Digitized data packets from these stations in WIN32 format (Urabe and Tsukada 1992; Shiomi et al. 2009) are continuously transmitted to the NIED DMC over Transmission Control Protocol/Internet Protocol (TCP/ IP) through an IP-VPN based on telephone lines (Obara et al. 2005). NIED and NTT-Com developed this transmission system, which is now operated by NTT-Com, for EarthLAN. To supply A/D converted data to the NIED DMC, NTT-Com operates a COMBOX at each station and at the EarthLAN control center. The COMBOX at each station continuously receives and stores data from the $\mathrm{A} / \mathrm{D}$ converter, and then sends the data to the control center. The control center integrates the data from $\mathrm{Hi}$ net stations, and directly sends them to the NIED DMC and JMA in Tokyo and Osaka at a latency of typically less than $0.5 \mathrm{~s}$. If there is packet loss, the COMBOX resends data according to a resending request from the control center. The COMBOX has sufficient storage capacity for 7-day worth of data and an uninterruptible power supply (UPS) that can operate for $24 \mathrm{~h}$ in the event of a power outage.
In 2002, a data exchange collaboration program was started among NIED, JMA, universities, and institutes. As a result, all Hi-net data are currently exchanged through the TDX installed in the EarthLAN control center, except for Hi-net data which are directly sent to the NIED DMC and JMA. Every day, the NIED DMC receives and stores approximately $70 \mathrm{~GB}$ of data in total from approximately 1500 stations belonging to $\mathrm{Hi}$-net, JMA, universities, and institutes across Japan. The data can also be accessed on the Internet approximately $2 \mathrm{~h}$ after its acquisition. In the early 2000s, it was impossible to keep all the stored data available on searchable disk storage due to size limitations. Today, disk storage capable of holding several hundred terabytes of data is available, so Internet users can access all of the stored data on the Hi-net website.

\section{Contributions}

Acquired data are automatically analyzed for quality control and research utility at NIED. The approximately 300 to 900 earthquakes that are identified every day are shown on the Hi-net website. In the case of major earthquakes, the results and their interpretations are reported to the HERP Earthquake Research Committee.

Densely deployed stations and observations with high dynamic range in the quiet conditions at borehole bottoms are advantageous for detecting microearthquakes. Obara et al. (2005) showed that the ability to detect crustal microearthquakes with magnitudes of 1.5 to 0.9 in the Wakayama area in southwestern Japan was improved by Hi-net. Shiomi et al. (2009) showed similar improvements for the Chugoku area in southwestern Japan.

A long-history hypocenter catalog can be a useful tool for background seismicity investigations. Figure 3 shows the distribution of shallow earthquakes that have occurred in central Japan over the last 19 years. We can identify many earthquake clusters, several of which correspond to recent moderate earthquakes and their aftershocks, while others are related to historical earthquakes such as the 1891 Nobi earthquake, or active faults such as the Itoigawa-Shizuoka Tectonic Line active fault system (The Headquarters for Earthquake Research Promotion 2015). The 1891 Nobi earthquake is one of the largest crustal earthquakes in recorded Japanese history. The time decay of aftershock activity for this earthquake was investigated by Utsu (1961). According to his empirical equation of time-dependent aftershock decay, the recent seismicity of felt aftershocks is expected to be approximately four events per year. Assuming that the minimum magnitude of a felt earthquake is approximately $\mathrm{Mj} 3.0$ and has a b-value of 1.0, the seismicity of microearthquakes with magnitudes larger than 1.0 is expected to be approximately 400 events per year. Because recent 


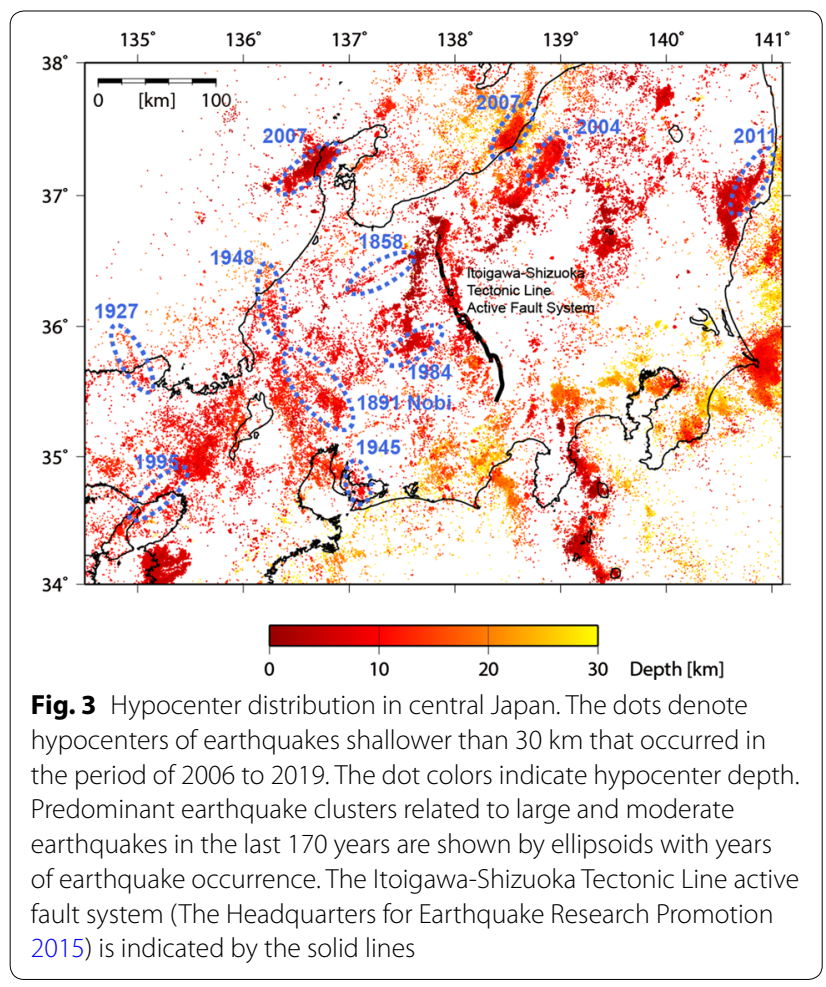

observed seismicity is consistent with model-predicted aftershock activity, the seismicity of this cluster can be considered to be the aftershocks of the 1891 Nobi earthquake.

More detailed hypocenter distributions have been investigated using the double-difference relocation technique (Waldhauser and Ellsworth 2000). For example, Yano et al. (2017) relocated 1.1 million shallow earthquakes that occurred in inland areas all over Japan and provided their results as the Japan Unified hI-resolution relocated Catalog for Earthquakes (JUICE) on the Hi-net website (www.hinet.bosai.go.jp/topics/JUICE /?LANG=en, Accessed 30 Apr 2020). They also showed that the seismogenic depth inferred from this catalog agrees with a recent moderate earthquake in central Japan.

\section{K-NET and KiK-net \\ K-NET and KiK-net overview}

NIED currently operates two large strong motion networks, K-NET and KiK-net (Kinoshita 1998; Aoi et al. 2004, 2011; Fujiwara et al. 2007; Kunugi et al. 2009; Fig. 1 and Additional file 1: Figure S2). After the 1995 Kobe earthquake, K-NET was planned as a nationwide strong motion seismograph network research project of NIED. The "K" in K-NET is an abbreviation for the Japanese word "kyoshin", which means strong ground motion. The
K-NET construction plan is based on the Basic Plan for Nationwide Deployment of Strong Motion Seismographs (Strong-Motion Earthquake Observation Council 1988) formulated by the Strong-Motion Earthquake Observation Council in 1988. This plan called for the uniform deployment of several thousand strong motion seismographs throughout Japan.

Later, when HERP established policies regarding the fundamental survey and observation for earthquake research, it was recommended that a strong motion seismometer and a high-sensitivity seismometer be installed together at each station to prevent the saturation of seismic records due to strong motions. Following that recommendation, NIED installed accelerometers on the ground surface and at the bottom of each borehole as a vertical array, in addition to high-sensitivity seismometers, at newly constructed Hi-net stations. The strong motion seismograph network, which consists of stations with these surface and downhole accelerometer pairs, operates independently as KiK-net. The name "KiK-net" refers to the strong motion network planned under the fundamental survey and observation for earthquake research because the Japanese word "kiban" means fundamental.

K-NET began operations in June 1996, just one and half years after the 1995 Kobe earthquake. The network initially consisted of 1000 stations, separated by an average distance of about $20 \mathrm{~km}$. Later, more stations with threecomponent strong motion accelerometers were added, including stations installed before 1995 and six accelerometer-equipped seafloor stations of the ETMC system in the Sagami Bay (Eguchi et al. 1998). Currently, the number of stations is 1037. Because K-NET was designed to record strong motions in residential areas, most stations are located on the grounds of public spaces such as government office buildings, schools, and parks. Each K-NET station is equipped with standardized observation facilities that are installed on a site $3 \mathrm{~m} \times 3 \mathrm{~m}$ square. A typical station consists of a lightweight hut made of fiber-reinforced plastic (FRP), a concrete base on which a set of accelerometers and recorders is installed, facilities for electric power and communications, and a protective fence. The hut is designed to withstand $4 \mathrm{~m}$ of snow. In places where the temperature falls below -20 degrees Celsius, the base on which the seismograph is installed extends from the ground surface to approximately $80 \mathrm{~cm}$.

KiK-net is a strong motion seismograph network consisting of pairs of accelerometers installed at the ground surface and at the bottom of a borehole, and each KiK-net station shares a borehole and observation facilities with a $\mathrm{Hi}$-net station. Currently, KiK-net consists of about 700 stations separated by an average distance of about $20 \mathrm{~km}$. The network covers almost all of the Japan Islands, except 
for Okinawa Prefecture and most remote islands. Most KiK-net stations are located on rock or mostly rock sites covered with a thin weathered layer because they share facilities with Hi-net stations that are designed for microearthquake observations. Each KiK-net station has an observation borehole drilled to a depth of $100 \mathrm{~m}$ or more. 13 stations have boreholes deeper than $2000 \mathrm{~m}, 12$ of which are in the Kanto region and the other (OSKH02) is located in Konohana, Osaka Prefecture. The deepest KiKnet borehole (SITH01), which is $3510 \mathrm{~m}$ deep, is located in Iwatsuki, Saitama Prefecture, and it is currently the deepest observation facility for strong ground motion in Japan.

\section{Observation instruments}

All of the strong motion seismographs installed at K-NET stations, K-NET95, K-NET02, K-NET02A, and K-NET11 listed in order of development, are specially designed for use by this network. At this point in time, all K-NET95 and K-NET02 have been replaced by K-NET02A and K-NET11.

K-NET95, the first-generation seismograph developed for K-NET, is manufactured by Akashi Co., Ltd. and consists of a three-component accelerometer and a data logger equipped with a 24-bit A/D converter with a sampling frequency of $100 \mathrm{~Hz}$. The maximum measurable acceleration is $\pm 2000 \mathrm{~cm} / \mathrm{s} / \mathrm{s}$ and the effective dynamic range is $114 \mathrm{~dB}$ or more. A V403BT accelerometer with a nominal full-scale range of $\pm 3 g$, manufactured by Akashi Co., Ltd., is used. The internal clock of the recording system, which has a precision of one $\mathrm{ppm}$, is calibrated by the Global Positioning System (GPS) signal every hour to provide an accuracy of five ms. During a power outage, K-NET95 can function for about $20 \mathrm{~h}$ using its built-in battery. K-NET95 is equipped with $8 \mathrm{MB}$ of flash memory and can store a total of about $2.5 \mathrm{~h}$ of three-component data digitized at a sampling frequency of $100 \mathrm{~Hz}$. Strong motion data are stored only when the ground acceleration exceeds the pre-set trigger condition. The data stored in K-NET95 can be obtained over dial-up connection from the NIED DMC.

K-NET02, the second-generation K-NET seismograph developed to replace K-NET95, is manufactured by OYO Corporation and began operating in 2003. K-NET02 is improved to measure a maximum acceleration of $\pm 4000 \mathrm{~cm} / \mathrm{s} / \mathrm{s}$ and has an effective dynamic range of more than $132 \mathrm{~dB}$. K-NET02 is equipped with $512 \mathrm{MB}$ of flash memory and a 24-bit A/D converter with a sampling frequency of $100 \mathrm{~Hz}$. The timing accuracy is improved to be $0.1 \mathrm{~ms}$. K-NET02 is equipped with an EpiSensor FBAES-deck, manufactured by Kinemetrics, Inc., which has a nominal full-scale range of $\pm 4 g$. One of the advantages of K-NET02 and later seismograph models is that they use the Linux operating system (OS), which means that they can be easily programmed to perform a wide variety of functions. K-NET02, K-NET02A, and K-NET11 can share most programs because they use the same OS. K-NET02 automatically establishes a connection over a telephone line to the NIED DMC within a few seconds after being triggered by an event, and can send waveform data even while recording. This feature significantly reduces the time required to collect data and telephone line congestion, which often occurs immediately after a major earthquake. K-NET02 is officially approved by JMA as a seismic intensity meter, and seismic intensity is automatically measured and sent to the NIED DMC within $1 \mathrm{~min}$ after triggering. The seismic intensities recorded by K-NET are broadcast within one and half to two minutes on television, radio, and the Internet through JMA. This information contributes to the decision-making and actions of national and local governments and private sector post-earthquake responses. During a power outage, K-NET02 can record strong motion data for 7 days using its backup battery and send seismic intensity data to the NIED DMC for 1 day.

K-NET02A is a modified version of K-NET02 that uses a different accelerometer JA-40GA04, which has a nominal full-scale range of $\pm 4 g$ and is manufactured by Japan Aviation Electronics Industry, Ltd. Because the hinge supporting the proof mass of this accelerometer is made of quartz, the generation of step-wise noise at the output is greatly reduced compared to that for accelerometers with metal hinges, such as those used in K-NET95 and K-NET02. This is important because even though the amplitude of step-wise noise is very small on a raw accelerogram, it can have a considerable effect on the velocity or displacement seismograms calculated from the integration of accelerogram data. Hence, a significant advantage of K-NET02A is its ability to reduce instability.

K-NET11, the third-generation K-NET seismograph, is currently the latest model in use. It is manufactured by OYO Corp. and its installation began in 2012 . K-NET11 has a maximum measurable acceleration of $\pm 8000 \mathrm{~cm} / \mathrm{s} / \mathrm{s}, 512 \mathrm{MB}$ of flash memory, and a 24-bit A/D converter with a sampling frequency of $100 \mathrm{~Hz}$. The accelerometer is JA-40GA08, which has a nominal fullscale range of $\pm 8 \mathrm{~g}$. During a power outage, K-NET11 can record strong motion data and send seismic intensity data to the NIED DMC for up to seven days. In addition, K-NET11 is equipped with a redundant accelerometer aligned on the skew axis, which is not parallel to any axis of the remaining three orthogonal accelerometers. This redundancy provided by observing three-component ground motion using a four-component sensor can be used for detecting accelerometer or A/D converter errors. 
All of the strong motion seismographs installed in KiKnet stations, SMAC-MDK, KiK-net06, and KiK-net11 listed in order of development, are specifically designed for use by this network. As of this time, all SMAC-MDK have been replaced, and KiK-net06 and KiK-net11 are currently in operation. The instruments used in K-NET and KiK-net are based on the same technology.

SMAC-MDK, the first-generation KiK-net seismograph, is manufactured by Akashi Co., Ltd., and includes a three-component V404BT accelerometer with a nominal full-scale range of $\pm 3 g$ for surface observations and a data logger equipped with a 24-bit A/D converter with a sampling frequency of $200 \mathrm{~Hz}$. The six-channel A/D converter uses three channels to digitize the three-component accelerometers at the surface and the other three channels to digitize the three-component accelerometers in the borehole. The acceleration resolution, maximum measurable acceleration, and effective dynamic range are $1 \mu \mathrm{m} / \mathrm{s} / \mathrm{s}, \pm 2000 \mathrm{~cm} / \mathrm{s} / \mathrm{s}$, and $114 \mathrm{~dB}$, respectively, which match the K-NET95 specifications. SMAC-MDK is equipped with $85 \mathrm{MB}$ of flash memory, which allows it to store a total of about $6.5 \mathrm{~h}$ of six-component data digitized at a sampling frequency of $200 \mathrm{~Hz}$.

The accelerometers currently installed in KiK-net boreholes are V404BT, V410BT, and JA-40GA04. The accelerometer employed at the time of construction of the Hi-net and KiK-net stations was V404BT. At some stations, V404BT has been replaced by V410BT, which is the successor to V404BT, or JA-40GA04. These accelerometers and the Hi-net velocity meters are mounted in a pressure-resistant vessel. Here, it should be noted that accelerometer replacement in station boreholes is performed independently from the seismographs at the ground surface.

KiK-net06, the second-generation KiK-net seismograph, is developed based on K-NET02A, and it has a 24-bit $A / D$ converter with a sampling frequency of $100 \mathrm{~Hz}$ and is equipped with a JA-40GA04 accelerometer.

KiK-net11, the third-generation KiK-net seismograph developed based on K-NET11, is currently in operation, and the K-NET11 and KiK-net11 have many components in common. KiK-net11 began operating in 2012. KiK-net11 has a 24-bit A/D converter with a sampling frequency of $100 \mathrm{~Hz}$ and uses JA-40GA08 for surface observations. Both KiK-net06 and KiK-net11 share bandwidth with EarthLAN to continuously transmit strong motion indices such as real-time seismic intensity (Kunugi et al. 2008, 2013), long-period ground motion intensity (Aoi et al. 2020a), peak ground acceleration (PGA), and response spectrum each second or at an optional timing. Furthermore, at some stations located in the Kanto area, KiK-net06 and KiK-net11 estimate earthquake epicentral distance and magnitude using the algorithm of Tsukada et al. (2004) and then transmit this information to JMA through EarthLAN for use in earthquake early warning.

\section{Data collection, archiving, and dissemination}

Previously, strong motion data recorded by K-NET95 and SMAC-MDK were collected over dial-up connections from the NIED DMC where the operation was automatically processed. However, data collection was often delayed due to telephone line congestion after a large earthquake. To solve this problem, a new data collection system was introduced in 2003 and has since been updated. In the current system, when a seismograph is triggered by ground motion exceeding a threshold that is set prior to the event, it automatically sends waveforms and seismic intensity data to the DMC at Tsukuba using more than 1000 telephone lines. The seismographs also send seismic intensity values of three or greater in parallel to the sub DMC located in Miki, Hyogo Prefecture, for robustness. The received seismic intensity data are transferred to JMA independently from not only the DMC in Tsukuba, but also the sub DMC in Miki within one and half minutes after an earthquake.

The collected waveform data are archived and provided on the K-NET and KiK-net website. To download data, users can select specific events or stations based on key parameter combinations. Users can also browse, select, and obtain various types of information such as acceleration distribution maps and station maps. The soil condition data surveyed at K-NET stations and the geological and geophysical data derived from drilled boreholes at KiK-net stations are also available. All of the archived waveform data are manually verified, and operators exclude inappropriate data such as traffic noise and link strong motion data to earthquake events.

\section{F-net \\ F-net overview}

NIED began construction of a broadband seismic observation network as part of the Fundamental Research on Earthquakes and Earth's Interior Anomaly (FREESIA) project in 1994 (Fukuyama et al. 1996). The aim of this project is to gain a better understanding of the earthquake source process, detailed structures of the crust and upper mantle, and deeper parts of the Earth's structure. A total of 20 FREESIA stations had been constructed by March 1997. After that, based on the HERP policy, NIED constructed a broadband observation network covering the Japan Islands with station intervals of about $100 \mathrm{~km}$, and the FREESIA network was integrated into the network in April 2001. The integrated broadband seismograph network was named Full Range Seismograph Network of Japan (F-net) in April 2002. The total number 
of F-net stations reached 73 (Matsumoto et al. 2009; Fig. 1 and Additional file 1: Figure S3). The network now covers almost all of Japan, including remote Izu, Ogasawara, and Ryukyu Islands. Because broadband seismographs are significantly affected by temperature changes, the seismographs at most F-net stations are installed at the end of dead-end tunnels with a length of 20 to $60 \mathrm{~m}$, where the sensitive instruments are isolated from outside weather effects by several boundaries. At 25 stations, vault-type seismic and/or geodetic observatories owned by various universities are operated as F-net stations under joint research agreements between NIED and the universities. At some observatories, NIED uses vaults constructed for purposes other than broadband seismic observations such as a railway tunnel of dead tracks and a tunnel at a dam. Nine and three stations have vaults longer than $60 \mathrm{~m}$ and shorter than $20 \mathrm{~m}$, respectively, and seismometers at the Sapporo station are installed in a vertical shaft.

\section{Observation instruments}

For broadband seismic observations, two types of sensors are installed at each F-net station. As broadband sensors, STS-1 (Wieland and Streckeisen 1982) or STS2, manufactured by G. Streckeisen AG, whose responses are flat to ground velocity from 0.1 to $360 \mathrm{~s}$ and from 0.1 to $120 \mathrm{~s}$, respectively, are installed. In addition, CMG-1T and CMG-3T sensors manufactured by Guralp Systems Ltd. were used at some F-net stations until 2002. STS2.5 manufactured by Kinemetrics Inc. has been used as a successor to STS-2 at some stations since 2014. The numbers of stations with STS-1, STS-2, and STS-2.5 sensors are 16, 39, and 18, respectively. These broadband sensors have a clip level of about $\pm 10 \mathrm{~mm} / \mathrm{s}$ and cannot observe ground motions caused by regional large earthquakes around Japan. Therefore, a velocity-type strong motion sensor is also installed at each F-net station to extend the dynamic range of the observations. The VSE355G3 sensor manufactured by Tokyo Sokushin Co. Ltd., which has a flat response to ground velocity from 0.008 to $70 \mathrm{~Hz}$ and a clip level of $\pm 2 \mathrm{~m} / \mathrm{s}$, along with the TSM-1 sensor manufactured by Tokyo Keiki Inc., which has a flat response to ground velocity from 0.01 to $80 \mathrm{~Hz}$ and the clip level of $\pm 3 \mathrm{~m} / \mathrm{s}$, are installed at 62 and 11 stations, respectively.

Until 2003, Quanterra Q680 was used as a data logger. Observation data were digitized with 24-bit A/D converters that had sampling frequencies of $80,20,1,0.1$, and $0.01 \mathrm{~Hz}$, and were time-stamped based on GPS time information. Later, to facilitate more rational operation of all NIED observation networks, data logger systems that were compatible with those used by $\mathrm{Hi}$-net were installed at F-net stations. At present, data loggers with 27-bit
A/D converters and sampling frequencies of $100 \mathrm{~Hz}$ are installed at all F-net stations.

\section{Data management system and data distribution}

In the FREESIA network, observed real-time data are continuously transmitted from each station to the NIED DMC over a $64 \mathrm{Kbps}$ dedicated telephone line. At present, WIN32 format waveform data with $100 \mathrm{~Hz}$ sampling are directly transmitted through EarthLAN to both the NIED DMC and JMA. Moreover, international real-time data exchange is performed with Korea Meteorological Administration (KMA), Korea Institute of Geoscience and Mineral Resources (KIGAM), and Institute of Earth Sciences, Academia Sinica, Taiwan. The observed waveform data acquired at the NIED DMC are provided to the public on the NIED websites. For the convenience of researchers that use broadband waveforms, the $100 \mathrm{~Hz}$ data are routinely converted at the NIED DMC into 20 and $1 \mathrm{~Hz}$ sampling data and made available on the F-net website.

\section{Quality control of observed waveform data}

Most of the STS-1 and STS-2 seismometers have been in operation for about 20 years and it is thus possible that these sensors have degraded in terms of their response to ground motion and noise levels. To determine the conditions of the instruments, NIED developed a system for monitoring the quality of waveform data that consists of two subsystems. One monitors the instrument response to ground motion (Kimura et al. 2015) and the other monitors the background noise in the waveform data (McNamara and Buland 2004). These subsystems enable us to monitor the instrument conditions without inputting a calibration signal not to disturb the continuous waveform data. The output of these systems is used to detect instrument errors in F-net operation and is provided to users on the F-net website.

For response monitoring, Kimura et al. (2015) developed a method to compare waveform data at a target station with periods of 50-200 s, which result from large shallow teleseismic events, with those at several nearby stations. Because the long-period surface waveform observed at the target station will be almost identical to those observed at nearby stations, after the observed waveforms have been corrected with the reported instrumental responses, the differences among the waveforms can be used to evaluate any errors in the responses. This method has enabled us to confirm the normality of the responses for most of the stations for the period from 1995 to 2013 and has revealed errors at some stations, especially those equipped with STS-1 seismometers. In the monitoring system, this method is routinely applied to teleseismic observation data, and is used to detect 
temporal changes in the instrument responses. In the other system, the power spectral densities (PSDs) of continuous waveform data at each station are routinely calculated using the method devised by McNamara and Buland (2004). The probability density function of the calculated PSDs enables us to monitor the characteristics of background noise in waveform data, as well as their temporal changes.

\section{Moment tensor analysis using F-net waveform data}

Using the F-net waveform data, automated moment tensor (MT) analyses of regional earthquakes (Dreger and Helmberger 1993) have been performed by NIED since 1997 (Fukuyama et al. 1998; Kubo et al. 2002). In this system, earthquake information from JMA triggers an automated inversion analysis when an earthquake is $\mathrm{Mj} 3.5$ or larger, and an inversion analysis is performed using the F-net waveform data with a period of 20 to $200 \mathrm{~s}$ at three or fewer stations. The analyzed MT results are automatically displayed on the F-net website within approximately $7 \mathrm{~min}$ after the origin time. The automatically determined MT solutions are then reviewed manually to improve their accuracy and reliability, and the F-net website information is revised if necessary. The total number of events in the F-net MT catalog currently reaches 38,000 .

Matsumura et al. (2006) developed another automated source-parameter estimation system called the Accurate and QUick Analysis System for Source Parameters (AQUA). In operation, the AQUA system first performs earthquake detection, and estimates the hypocenter location and magnitude using three algorithms: the real-time earthquake information system (Horiuchi et al. 2005; Nakamura et al. 2009), the wavefront estimation method, and the conventional hypocenter location method based on the Hi-net data. The resulting estimated parameters are used as the initial values of the latter two-moment tensor analyses, with the horizontal location fixed to the initial value (AQUA-MT), and with hypocenter searching (AQUA-CMT) where F-net data from at most 20 stations are used. From the time of earthquake detection, it takes less than $30 \mathrm{~s}$ for the initial hypocenter information estimation, 2 to $5 \mathrm{~min}$ for the AQUA-MT analysis, and 4 to 8 min for the AQUACMT analysis. The MT and CMT solutions as well as the hypocenter information estimated by the AQUA system are posted on the Hi-net website immediately after an earthquake (www.hinet.bosai.go.jp/AQUA/aqua_catal ogue.php?LANG=en, Accessed 30 Apr 2020). The combined use of F-net broadband and strong motion data has recently improved the accuracy of magnitude estimation for M9-class large earthquakes by the AQUA analyses (e.g., Kimura et al. 2020) such as those of the 2011 Tohoku earthquake.

\section{Earthquake and tsunami observation networks on seafloor \\ S-net \\ Background and purpose of S-net construction}

S-net, the world's largest seafloor observation network, consists of cable-linked seismic and tsunami observatories along the Japan and Kuril Trenches (Kanazawa et al. 2016; Mochizuki et al. 2016; Uehira et al. 2016). It includes 150 real-time monitoring observatories that cover an area of about $1000 \mathrm{~km} \times 300 \mathrm{~km}$ along the Pacific offshore of eastern Japan from Chiba Prefecture to Hokkaido Prefecture (Figs. 1, 4, and Additional file 1: Figure S4). Construction of S-net started in 2011 after the 2011 Tohoku earthquake and tsunami, and finished in 2017. One of the lessons learned from the aftermath of the 2011 Tohoku earthquake and tsunami was that accurate information on earthquakes and tsunamis cannot be obtained from data from only land-based seismic observation networks. At the time of the 2011 Tohoku earthquake and tsunami, the number of permanent onland seismic stations was more than 1400, however, only 45 stations covered the seafloor, ten of which were installed off the regions from Chiba Prefecture to Hokkaido Prefecture. When major earthquakes occur under

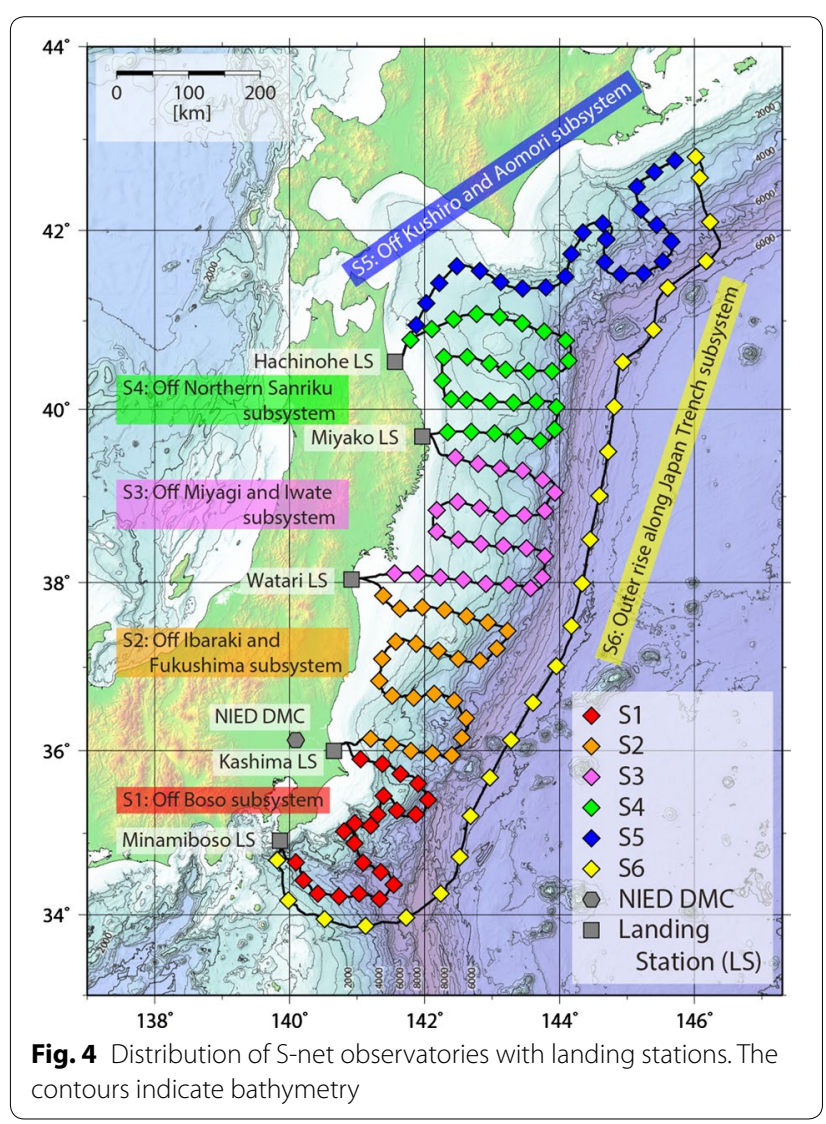


the sea, it is possible to detect them much earlier using seismic observations taken in sea areas and thus issue earthquake early warning and tsunami warning much earlier. Large interplate earthquakes may still occur off the Pacific coast of the Tohoku region, especially in the northern, southern, and outer-rise regions of the 2011 Tohoku earthquake and tsunami (The Headquarters for Earthquake Research Promotion 2011), which means the risk of strong shaking events and large tsunamis remains.

$\mathrm{S}$-net contributes to provide reliable earthquake early warning and tsunami warning as well as plate subduction research including that related to earthquake generation. The monitoring of crustal activity using S-net data is expected to promote to the long-term forecasting of earthquakes by helping to clarify seismic activity at the plate boundary in and around the Japan and Kuril Trenches.

\section{S-net observation system}

S-net has a total of 150 observatories, each of which has observation and monitoring functions for earthquakes and tsunamis. The observatories are arranged at approximately $30 \mathrm{~km}$ intervals in the east-west direction perpendicular to the Japan Trench axis, and about 50 to $60 \mathrm{~km}$ intervals in the north-south direction along the Japan Trench axis (Fig. 4). S-net consists of six subsystems labeled S1 to S6, which are located off Boso, off Ibaraki and Fukushima, off Miyagi and Iwate, off northern Sanriku, off Kushiro and Aomori, and outer rise along the Japan Trench, respectively.

The S1 to S5 subsystems and the S6 subsystem began operation in May 2016 and April 2017, respectively. The observatories are connected by ocean bottom fiber optic cables of about $5500 \mathrm{~km}$ in total length. For each subsystem, observatories are connected to the landing station in series. Each subsystem has 22 to 28 observatories, and both ends of the ocean bottom fiber optic cables are landed except for those of the S5 and S6 subsystems. $\mathrm{S}$-net has a total of five landing stations; one in MinamiBoso, Chiba Prefecture, where the S1 and S6 subsystems are landed, one in Kashima, Ibaraki Prefecture where the S1 and S2 subsystems are landed, one in Watari, Miyagi Prefecture, where the S2 and S3 subsystems are landed, one in Miyako, Iwate Prefecture, where the S3 and S4 subsystems are landed, and one in Hachinohe, Aomori Prefecture, where the S4 and S5 subsystems are landed. S-net has adopted an inline system where each observatory is directly connected in a row to the main cable, and cable ships can simultaneously install both cables and observatories. As a result, the inline system is quickly able to cover a wide region at relatively low cost.

For redundancy, observation data are transmitted to the landing stations at both ends of the subsystem, and both landing stations feed electric power to the system except for the S5 and S6 subsystems. To prevent damage from fishery, reduce ground noise, and increase ground coupling, the observatories and cables installed in waters shallower than $1500 \mathrm{~m}$ are buried about one meter beneath the seafloor. The cylindrical vessel of an observatory, made by beryllium copper alloy, has a diameter of $34 \mathrm{~cm}$ and a length of $226 \mathrm{~cm}$, and is separated in the pressure exposed section and the pressure-resistant section (Fig. 5). The tsunami meters are installed in the pressure exposed section where the pressure is transparent to the outside of the vessel through the bellows and the diaphragm. The seismometers, optical amplifier units, communication units, power supply units, and other parts are installed in the pressure-resistant section. The two sections are connected for power supply and data transmission using the feedthroughs. For redundancy, an observatory is equipped with three types of seismometers and two pressure gauges (tsunami meters) of the same type.

One of the important objectives of S-net is to contribute to the improvement of the accuracy and speed of the JMA earthquake early warning system, which means that S-net needs to perform accurate and redundant seismic observations. Because seismometers may experience problems during operation, each observatory is equipped with two sets of voltage output strong motion accelerometers, conventional velocity seismometers, and frequency output accelerometers to provide redundancy in a wide dynamic range. None of these devices require gimbal mechanisms. For the first type of seismometer, the observatory is equipped with two types of JA-5TYPEIIIA three-component servo-accelerometers manufactured by Japan Aviation Electronics Industry, Ltd. These sensors have fixed measurable ranges of $\pm 2 g$ and $\pm 5 g$, respectively, as hardware settings. For the $\pm 2 g$ sensors, $\mathrm{a} \pm 0.0625 \mathrm{~g}$ measurable range is set with a programmable gain amplifier. For the second type of seismometer, each observatory is equipped with one set of OMNI2400 three-component conventional velocity seismometers with a natural frequency of $15 \mathrm{~Hz}$ manufactured by Geospace Technologies. For the third type of seismometer, each observatory is equipped with one set of 7000-2 three-component frequency output accelerometers with a measurable range of $\pm 2 g$ manufactured by Quartz Seismic Sensors, Inc. Two high-sensitivity pressure gauge units, either 8B7000-2-005 or 8B8000-2-005, manufactured by Paroscientific, Inc., are installed as tsunami meters. The temperature data of the installed pressure gauges are also sampled to enable real-time adjustment of the temperature during pressure measurements, and the water depth measurement resolution is expected to be less than $1 \mathrm{~cm}$. The landing stations are equipped 


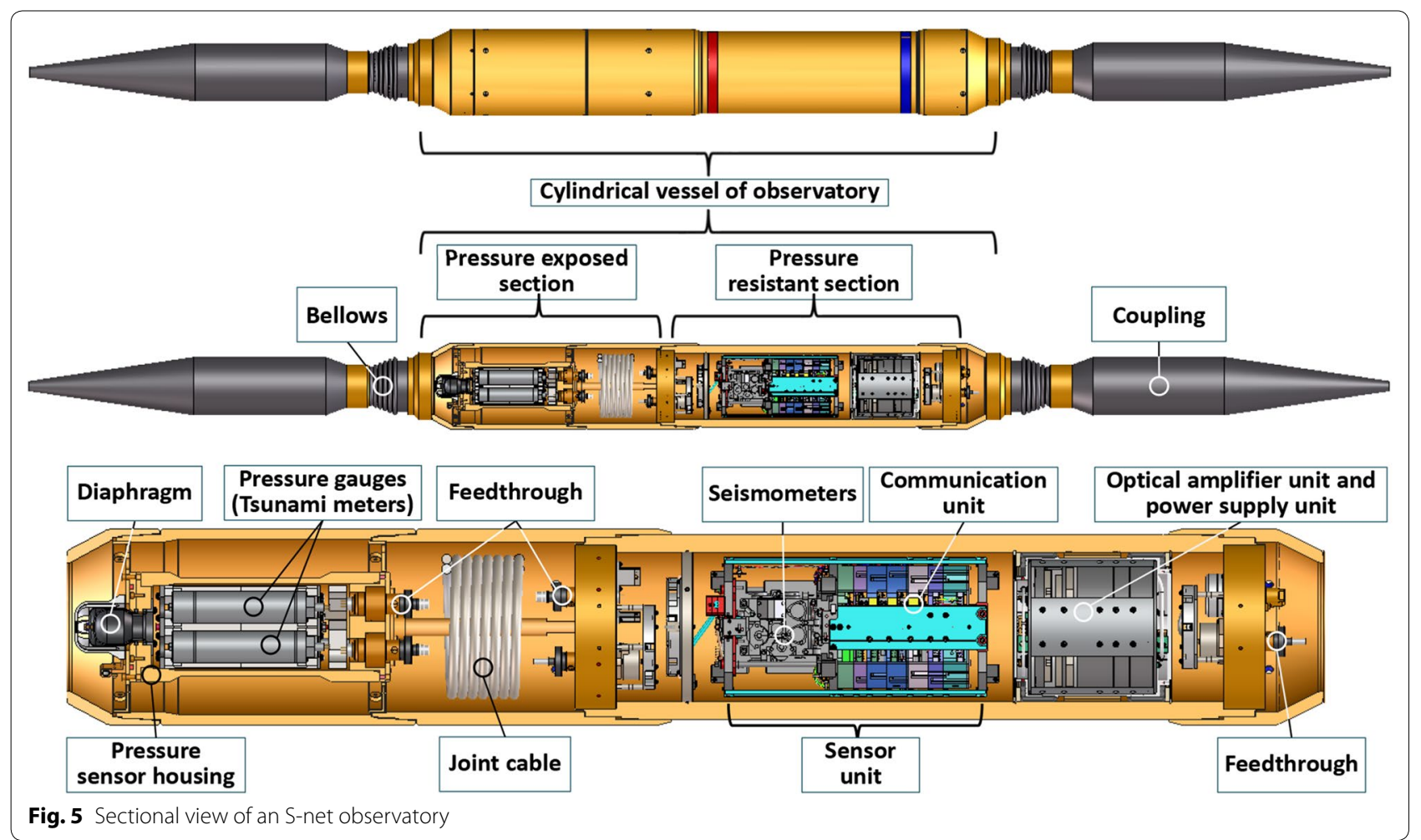

with a wide variety of terminal equipment such as power feeding equipment (PFE), supervisory and control equipment, optical receiver and transmission equipment, data conversion equipment, data transmission equipment, GPS clocks, UPSs, and an emergency power generator.

The observation data are time-stamped at the ocean bottom observatories based on GPS time information received from the landing station, and the high sampling rate data sent from each observatory are transmitted to the landing stations at both ends of the subsystem where they are converted into the original data using data conversion equipment and then transmitted through EarthLAN to the NIED DMC, JMA, and the backup center at ERI.

The PFE supplies power to the observatories through the ocean bottom cable with a 1.1 A constant current; therefore, the supply voltage determines the total supplied power. Power is consumed by the resistance of the ocean bottom cable as well as the observatories, and the total power required by a subsystem depends on the total length of the cable and the number of observatories. Because the supply voltage cannot exceed the designed withstanding voltage of the subsystem, there is a limitation on the length of the cable and the number of observatories that can be installed in a subsystem. Each landing station has an emergency power generator with more than a week's worth of fuel in case of a long-term power outage. This is important because a power outage of that length is expected in the aftermath of an event like the 2011 Tohoku earthquake and tsunami.

\section{DONET}

\section{DONET overview}

DONET is installed in rupture starting areas associated with the historical Tonankai and Nankai earthquakes where ruptures have repeatedly occurred with some variability (Figs. 1, 6, and S4). The development of the network was started in 2006 by JAMSTEC and ownership was transferred to NIED in 2016 (Kaneda et al. 2015; Kawaguchi et al. 2015). NIED currently has full responsibility for DONET operations.

The latest cycle was the 1944 Tonankai earthquake and the 1946 Nankai earthquake. The prior cycle was the 1854 Ansei Tonankai earthquake and the 1854 Ansei Nankai earthquake that occurred $32 \mathrm{~h}$ later. The rupture pattern of these Ansei events is similar to that of the recent events. However, because the general seismicity along the Nankai Trough is relatively low, there have been few M4+ events except the 2016 M6.5 off southeast Mie event since the network began operations. The aims of DONET are the observation of large events and the monitoring of crustal activity for earthquake forecasting, including crustal deformation and slow slip events (SSEs), using data assimilation and simulation techniques. DONET detects microearthquakes with a 


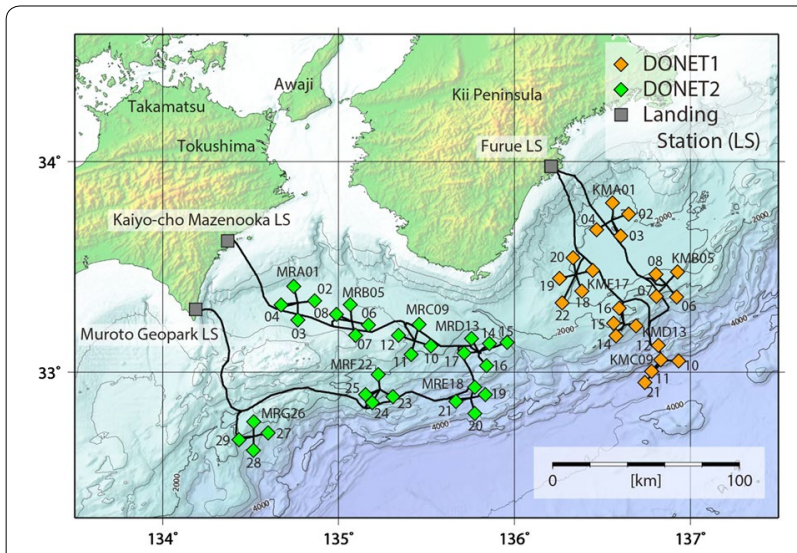

Fig. 6 Distribution of DONET observatories with landing stations. The contours indicate bathymetry magnitude of over 0.7 using a station array connected to one node. Considering the cycle process of major earthquakes along the plate boundary, which consists of the stages of preparation, pre-slip, rupture, and afterslip with crustal relaxation, it is particularly important to monitor crustal activity in rupture areas because the DONET area includes the anticipated rupture starting areas for the abovementioned events (e.g., Hori 2016).

DONET consists of two subsystems, DONET1, which has 22 observatories installed across the Kumano-Nada, and DONET2, which has 29 observatories installed off the Kii Channel. The total lengths of the ocean bottom cables for the two systems are approximately $300 \mathrm{~km}$ and $500 \mathrm{~km}$, respectively. Both ends of the loop-shaped DONET1 cable terminate at the Furue landing station located in Mie Prefecture, while the DONET2 cable terminates at the Kaiyo-cho Mazenooka landing station located in Tokushima Prefecture and the Muroto Geopark landing station located in Kochi Prefecture (Fig. 6). DONET1 and DONET2 have five and seven science nodes, respectively, and these nodes serve as seafloor adapters that supply electrical power to the observatories. DONET adopts a node system, where each science node is connected to the loop-shaped main cable via a terminal unit (TU), a double conductor cable, and a branching unit (BU), as shown in Figs. 7 and 8. All the observatories are connected to the science nodes via extension optical cables. The main cables were installed using cable ships, whereas the science nodes, extension cables, and observatories were installed using a remotely operated vehicle (ROV), and are designed to be replaceable when they require maintenance. All observatories have ground motion sensing systems equipped with two types of seismometers, and pressure sensing systems equipped with two types of pressure gauges, a hydrophone, and a precise thermometer.

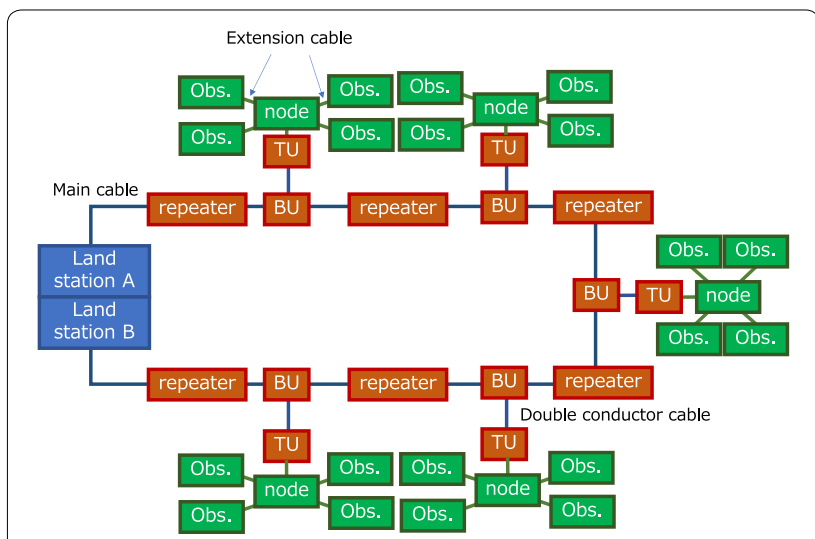

Fig. 7 Schematic outline of the DONET system. BU, TU, and Obs indicate branching units, terminal units, and observatories, respectively

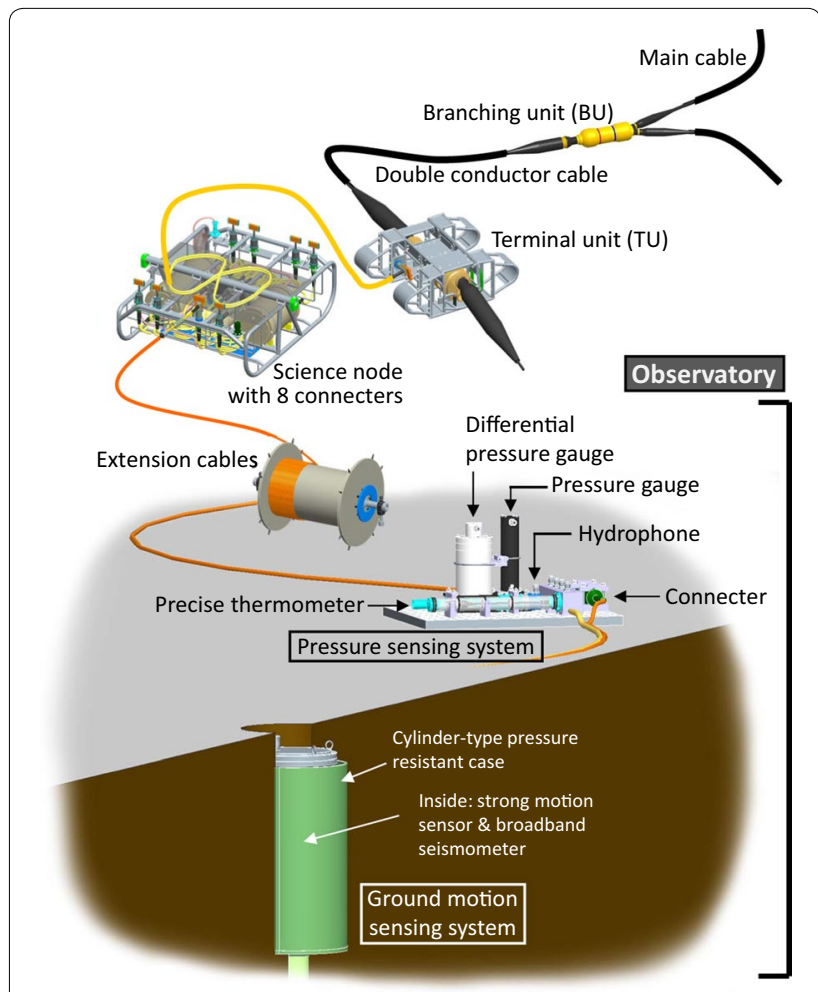

Fig. 8 Schematic view of the DONET system

DONET was established based on the four key concepts of reliability, redundancy, replaceability, and the ability to conduct a wide dynamic range of broad frequency band seafloor observations. According to the HERP Earthquake Research Committee, there is a $70 \%$ to $80 \%$ probability that a major earthquake will occur along the Nankai Trough within the next 30 years. Therefore, it is imperative to continue observations over the 
coming decades. DONET consists of an observation system that uses the general technology of commercial submarine communication cables which are buried $1 \mathrm{~m}$ beneath the seafloor in waters shallower than $1000 \mathrm{~m}$ in order to reduce the risk of cable damage due to fishery. However, such cables could still be damaged or severed by seafloor landslides. In fact, some commercial cables were disrupted by landslides related to the 2011 Tohoku earthquake. Because the ruptures of the past Tonankai and Nankai earthquakes were linked, it is essential that we continue observations for a long time to monitor the entire earthquake cycle. To ensure a system as reliable and redundant as S-net, the DONET cable has a looped shape that allows it to supply power to the seafloor observatories and collect data continuously even when problems occur within the cable. The aim of DONET is to observe and record events over a wide dynamic range, from small- to large-scale events, which means over a broad frequency band ranging from major crustal deformations to short-period strong ground motions.

\section{DONET sensors}

A DONET observatory contains both ground motion sensing and pressure sensing systems. The ground motion sensing system consists of a strong motion accelerometer and a broadband seismometer installed in a cylinder-type pressure-resistant case, which is emplaced about $1 \mathrm{~m}$ beneath the seafloor to reduce ground noise and increase ground coupling. The pressure sensing system consists of a pressure gauge, a differential pressure gauge, a hydrophone, and a precise thermometer assembled on a frame embedded on the seafloor. These systems allow events to be observed over a wide dynamic range and broad frequency band. The observatories maintain redundancy and observational capability of a broad frequency band and high dynamic range using many types of sensors. For the ground motion sensing system, the strong motion sensor and broadband seismometer are TSA-100S manufactured by Metrozet LLC and CMG3T manufactured by Guralp Systems, Ltd., respectively. For the pressure sensing system, the pressure gauge, hydrophone, differential pressure gauge, and precise thermometer are, respectively, the Series 8000 depth sensors manufactured by Paroscientific Inc., the HTI-90-U series hydrophone manufactured by HighTech Inc., the NPH Series Novasensor solid-state low-pressure sensor, and the Pt100 sensor probe, the latter two of which are assembled by NiGK Corporation.

\section{Data processing at landing stations and DMC}

The landing stations have several functions for seafloor observations. These include, for example, timestamp control and administration, conversion of optical signals to digital data, data decimation, and data transmission. The transmitted data are sent to the NIED DMC, the NIED Yokohama backup site located at JAMSTEC, JMA, local governments, and private sectors that use DONET data, as well as universities and research institutes. GPS timing signals are sent to seafloor observatories, where they are used to control A/D converter timing. Optical frequency signal data from seafloor observatories are converted to digital data at the landing station, where decimation is applied. At the Furue landing station of DONET1, all data are received from seafloor observatories via two routes, which run clockwise and counter-clockwise along the main cable. Data from each route are processed independently and then unified after being confirmed to be identical. In contrast, DONET2 has two landing stations, and the data are unified at the NIED DMC and the Yokohama backup site, where all data are compared before being stored. When data transmission has problems, the data can be compensated for. The data sampling rates are as follows. The low- and high-gain three-component strong motion sensors and broadband seismometers have sampling rates of both 100 and $200 \mathrm{~Hz}$. The sampling rate is $10 \mathrm{~Hz}$ for the pressure gauge, $200 \mathrm{~Hz}$ for the differential pressure gauge and hydrophone, and $1 \mathrm{~Hz}$ for the precise thermometer. The data of three-component strong motion sensors and broadband seismometers sampled at $100 \mathrm{~Hz}$ and pressure gauges sampled at $10 \mathrm{~Hz}$ are sent to the NIED DMC, JMA, and other organizations through EarthLAN. The NIED DMC archives all seismic and pressure data, which are then made available on the NIED website.

\section{Ongoing project along the Nankai Trough: $\mathrm{N}$-net}

Offshore observations offer a significant advantage for natural disaster prevention from such as the forthcoming Nankai Trough earthquake because they can detect earthquakes and tsunamis in unpopulated areas. However, because there are no real-time seafloor observatories in the western region of the Nankai Trough from off Kochi to the Hyuga-Nada, NIED has started the Nankai Trough Seafloor Observation Network for Earthquakes and Tsunamis (N-net) project under the sponsorship of the Ministry of Education, Culture, Sports, Science and Technology (MEXT) (Aoi et al. 2020b). NIED typically constructed networks in response to past earthquake disasters; however, $\mathrm{N}$-net is an epoch-making exception because it is constructed in anticipation of disastrous earthquakes. $\mathrm{N}$-net is also expected to contribute to earth science including understanding the plate coupling rate and the spatio-temporal changes of the slip conditions.

$\mathrm{N}$-net adopts a hybrid system based on the inline system adopted in S-net for quickly covering a wide region at relatively low cost and the node system adopted in 
DONET for expandability and flexibility. N-net consists of two (offshore and inshore) subsystems designed to link two landing stations between Muroto in Kochi Prefecture and Kushima in Miyazaki Prefecture. Each subsystem will have 18 inline stations connected to each other by main cables in a row. $\mathrm{N}$-net will have 36 stations and main cables approximately $1600 \mathrm{~km}$ long in total. Each subsystem has two BUs and these BUs are reserved for future expansion. To ensure redundancy, each inline station is equipped with two paired sets of accelerometers and short-period velocity seismometers to observe earthquakes and two sets of pressure gauges to observe tsunamis. By adding N-net to the existing observations, the first arrival times for earthquakes and tsunamis are, respectively, expected to shorten by a maximum of $20 \mathrm{~s}$ and $20 \mathrm{~min}$. The observation data will be transmitted to the NIED DMC as well as JMA in real time and used for earthquake early warning and tsunami warning, and the data will be open to the public.

\section{Volcano observation network \\ V-net \\ V-net overview}

Based on the proposition by the Geodesy Council of the Ministry of Education, Science and Culture (currently MEXT), the Volcanic Eruption Prediction Plan started in 1974, and NIED started continuous observations at active volcanoes in the 1980s (Tanada et al. 2017). During the first half of the 1980s, NIED constructed observation stations at Ioto based on the second Volcanic Eruption Prediction Plan. At that time, the Ioto stations were equipped solely with surface-level seismometers, but they now also have GNSS receivers. NIED also constructed volcano observation stations equipped with borehole-type short-period seismometers and tiltmeters on Izu-Oshima as a part of the Kanto and Tokai Crustal Activity Observation Network. On 21 November 1986, the installed tiltmeters detected the tilt change accompanying the magma rise immediately before the magmatic eruption on Izu-Oshima. This result confirmed that tiltmeters are effective tools for eruption prediction (Yamamoto et al. 1988). In 1989, when a submarine eruption occurred in the Izu-Tobu volcano group, the tiltmeter and GPS receivers detected tilt changes and crustal movements associated with earthquake swarm activity (Okada and Yamamoto 1991; Shimada et al. 1990). These crustal deformations were quantitatively explained by the Okada model (Okada 1985) as changes due to a dike intrusion, verifying the applicability of GPS and the Okada model to volcanic activity evaluation.

NIED started a research project on volcanic eruption prediction in 1989, and as part of that project, observation stations were constructed on Mt. Fuji, Miyake-jima
Island, and Mt. Nasu in the 1990s. On 26 June 2000, the observation stations on Miyake-jima Island detected tilt changes caused by rising magma before eruption (Ueda et al. 2005). Due to this anomaly, JMA issued volcanic warning and succeeded in predicting the eruption. After that, the stations observed seismic activity associated with the movement of a large amount of magma to the west, off the island and crustal deformations associated with magma chamber contraction. The activation of deep low-frequency earthquakes was observed by the Volcano Observation Network installed on Mt. Fuji in 2000. Although this earthquake activity did not lead to an eruption, it raised awareness of the need for disaster prevention in local areas around the country, and as a result, a hazard map for Mt. Fuji was created.

In 2008, the Committee on Earthquakes and Volcanoes, Subdivision on Geodesy and Geophysics, of the Council for Science and Technology of the Government of Japan, decided to focus on 16 active volcanoes with high research value, such as those with high activity and those with low current activity but high activity potential. The number of such volcanoes was increased to 25 in 2016. Based on this decision, NIED developed new volcano observation stations at 11 volcanoes during the period from 2009 to 2015. In 2011, NIED named this network of volcano observation stations the Fundamental Volcano Observation Network (V-net). Currently, NIED has established $55 \mathrm{~V}$-net stations on 16 active volcanoes (Fig. 1 and Additional file 1: Figure S5).

\section{Observation instruments}

A typical V-net station is equipped with a short-period seismometer and a tiltmeter at the bottom of a borehole from 100 to $200 \mathrm{~m}$ deep, a broadband seismometer in the station basement placed $2 \mathrm{~m}$ below the surface, and a GNSS antenna for precise ground surface positioning (Tanada et al. 2017). The stations on Ioto are limited to seismometers on the ground instead of borehole-type seismometers and tiltmeters due to the extremely high geothermal activity of the island.

ABS-143, a borehole-type integrated device manufactured by Mitutoyo Corporation, consists of a shortperiod seismometer and a tiltmeter. The seismometer can detect the micro- and low-frequency earthquakes that occur during magma movements, and the tiltmeter measures small changes in tilt due to magma ascent. The broadband seismometers, either Streckeisen STS-2 or Nanometrics Trillium 240, are installed to measure long-period seismic waves such as the long-period earthquakes associated with eruptions. They are also equipped with a rain gauge and a barometer to correct the tiltmeter. The analog output of the observation devices is digitized by a 27-bit A/D converter, and then, depending on 
the location, transmitted in real time to the NIED DMC over wired, satellite, or wireless communication.

GNSS can be used to measure ground deformation caused by the long-term expansion and contraction of magma chambers. The receivers are Trimble NetR9, Javad Delta-G3T, and Leica GR10. GNSS data are collected every hour over the File Transfer Protocol (FTP). After being receiving at NIED, V-net data are analyzed daily using Bernese GNSS Software (version 5.2) as Receiver Independent Exchange Format (RINEX) data together with data provided by GSI and JMA to determine the precise locations of the observation stations.

\section{Data management system and data distribution}

$\mathrm{V}$-net seismic data are transmitted in real time from the observation stations to NIED through EarthLAN as WIN32 format waveform data. NIED then exchanges the data in real time based on agreements with JMA and universities. JMA uses their data in combination with data from $\mathrm{V}$-net and other institutes to monitor active volcanoes and issue volcanic warnings. Data are archived at the NIED DMC and then provided on the Internet to interested researchers, and such data are widely used for academic purposes. The observational results and research results provided to CCPVE of JMA contribute to volcanic activity assessments. In addition to observation data, core samples obtained during the construction of V-net boreholes are used to research the eruption history of each observation site.

\section{MOWLAS data contributions Archive and open data}

As a national data center, NIED records and archives MOWLAS data, unifies the data from NIED, JMA, universities, and institutes, and makes the data freely available to the public on the NIED websites. MOWLAS data are processed comprehensively and openly provided as the JMA unified hypocenter catalog, and contribute as data fundamental for earth science, earthquake engineering, and disaster prevention. MOWLAS and its individual networks were assigned Digital Object Identifiers (DOIs) in 2019 to permanently identify and link them. The DOIs facilitate MOWLAS data use and citation (Table 1).

Figures 9 and 10 show summaries of the MOWLAS data statistics. The amount of continuous archived MOWLAS data is huge. In particular, data from Hi-net include more than 3.5 million hypocenters (Fig. 9a) covering 19 years and are $260 \mathrm{~TB}$ in size (Fig. 9d). Large earthquakes, including ten destructive earthquakes shown at the top of Fig. 9, have been followed by numerous aftershocks. These events are clearly shown in the monthly event numbers (Fig. 9a) and the magnitude distribution (Fig. 9b). Slow events, such as nonvolcanic tremors, very low-frequency earthquakes (VLFEs), and SSEs discovered after the construction of the Hi-net system, are now routinely detected and located (Fig. 9c).

In addition to original F-net waveform data, estimated results such as MT solutions are also provided. Figure 9e shows the temporal changes in the monthly and cumulative numbers of the F-net MT solutions. In 1997, MT solutions for 313 earthquakes were estimated. As the number of F-net stations increased, the number of MT solutions increased, reaching 1509 in 2003. After 2004, the number of the F-net stations remained almost constant and the annual number of MT solutions stabilized at around 1500, except in 2011 and 2012 due to the 2011 Tohoku earthquake. From June to August 2000, an earthquake swarm related to the eruption of Miyake-jima Island occurred in the Izu volcanic islands, and MT solutions for 926 earthquakes were estimated in July 2000. After the 2011 Tohoku earthquake, a large number of aftershocks occurred in and around the source area, and 6836 MT solutions were estimated during 2011. The total number of the F-net MT solutions had reached 38,180. Figure $9 \mathrm{f}$ shows the moment magnitude $\left(M_{\mathrm{w}}\right)$ of the MT solutions as a function of time. In the F-net MT catalog, the numbers of earthquakes with $M_{\mathrm{w}} \geq 7.0,6.0$, and 5.0 are 34,313 , and 2788, respectively. In Fig. 9a, b, magnitudes are evaluated from maximum velocity amplitudes based on an empirical formula (Watanabe 1971). The magnitudes of some deep and/or distant earthquakes for the four main islands of Japan seem to be larger than the moment magnitudes determined by F-net (Fig. 9e, 9f).

The archive of the K-NET and KiK-net triggered data contains about 0.8 million records for approximately 17,000 earthquakes. Figure 10a shows the monthly and cumulative numbers of earthquake events in the archive, and Fig. 10b shows those of the strong motion records in the archives. Figure 10c, d, and e shows the PGA, peak ground velocity (PGV), and the JMA seismic intensity calculated from the records, respectively. Among the remarkable records, K-NET and KiK-net have recorded events with a JMA seismic intensity of 7 four times and events with that of 6 lower or 6 upper 188 times. In terms of PGA for the vector sum of three-component accelerograms on the surface, K-NET and KiK-net have recorded more than $1000 \mathrm{~cm} / \mathrm{s} / \mathrm{s} 42$ times. The records include the data obtained with the KiK-net06 seismograph at IWTH25 (Ichinoseki-West), which was directly above the reverse fault during the $2008 M_{\mathrm{w}} 6.9$ Iwate-Miyagi earthquake. The data indicate that the observed PGA was $4022 \mathrm{~cm} / \mathrm{s} / \mathrm{s}$, the largest value recorded in the world, and that the PGA of the UD component on the surface was $3866 \mathrm{~cm} / \mathrm{s} / \mathrm{s}$, which would not have been possible to 


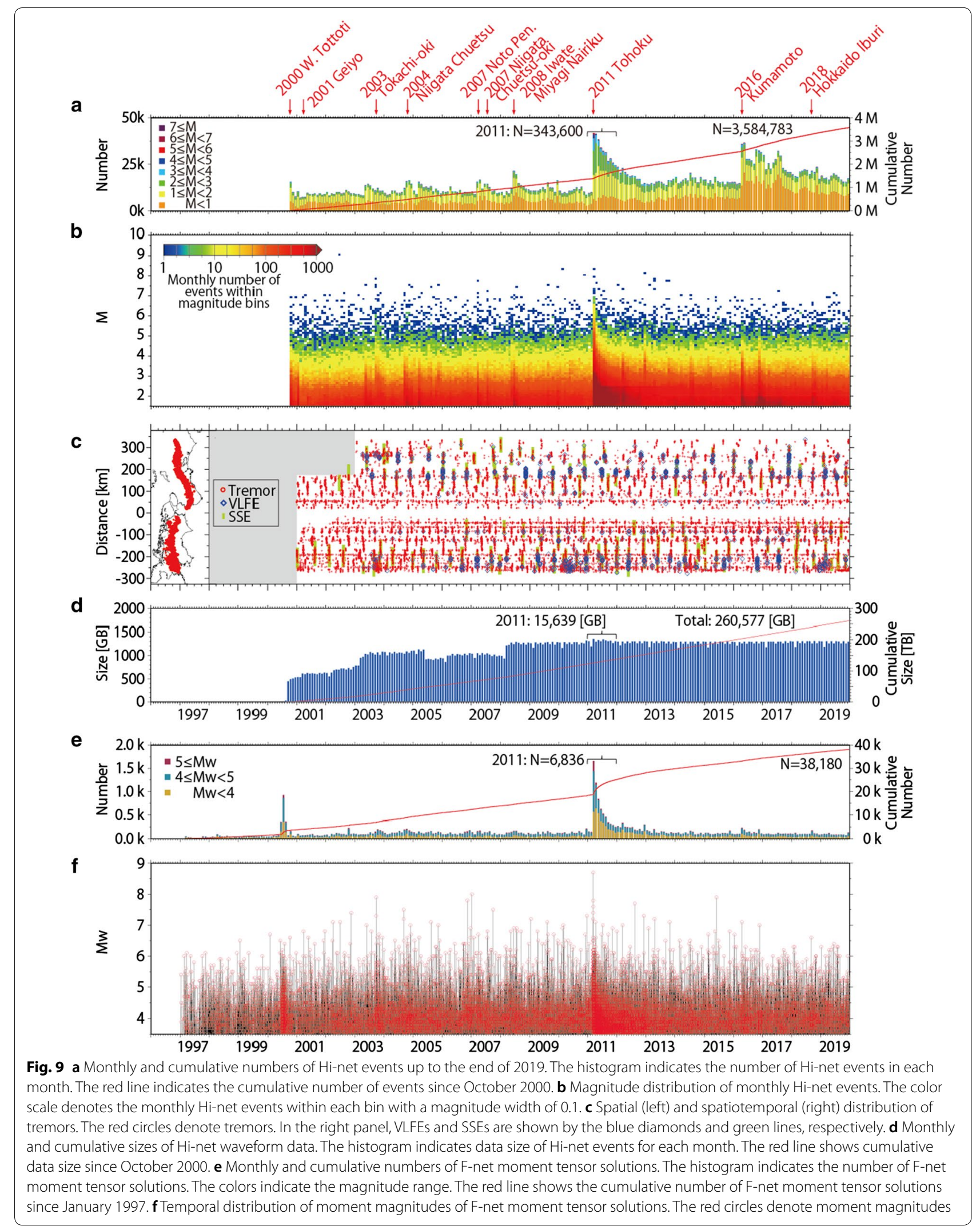




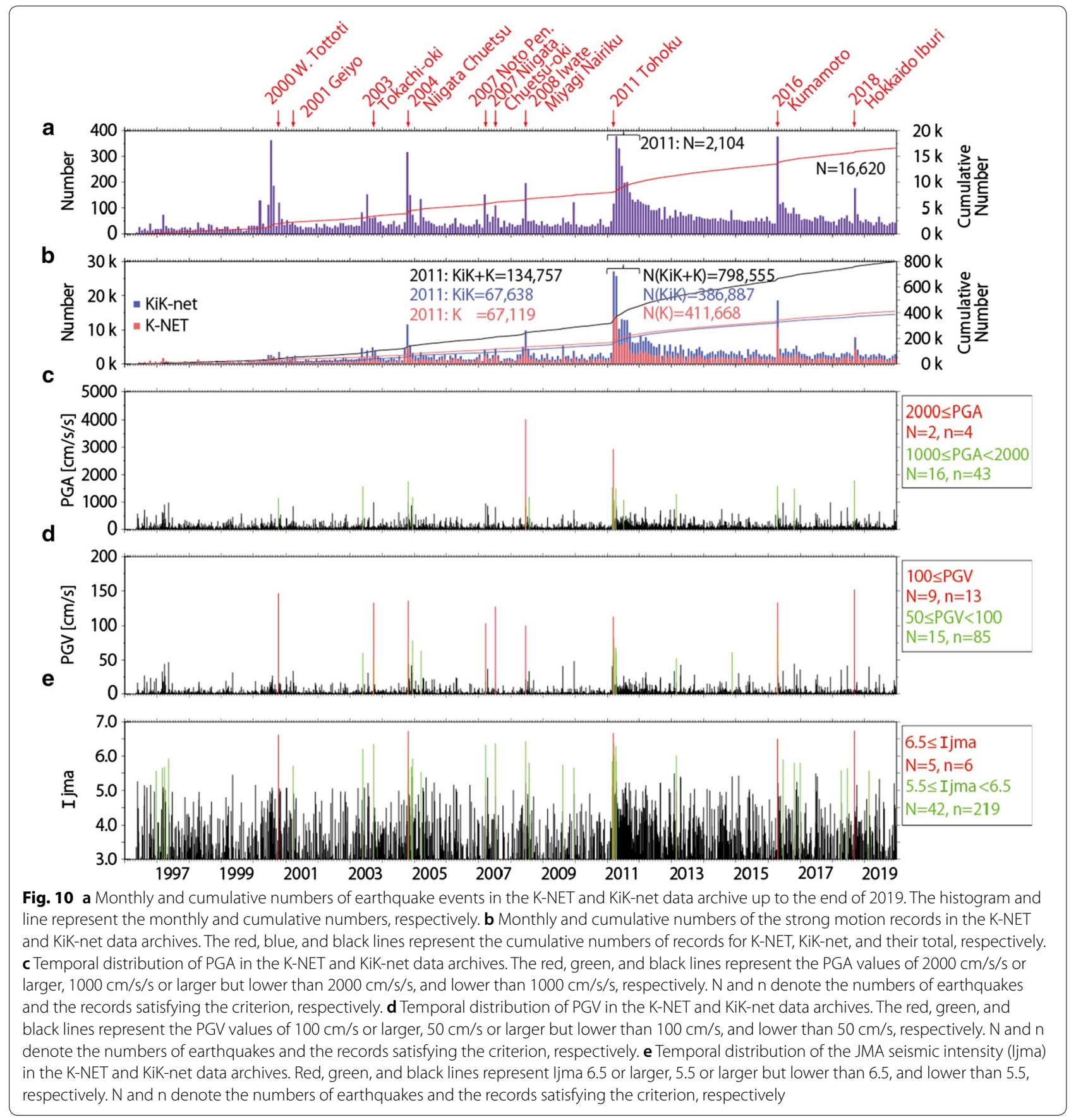

record without saturation using SMAC-MDK alone. The waveform and envelope of the UD component on the surface are strongly asymmetric, and contributed to the discovery of the trampoline effect (Aoi et al. 2008).

The 2011 Tohoku earthquake is the largest instrumentally recorded earthquake in Japan to date. The strong motions from this devastating earthquake were felt over almost all of Japan, with severe 6 lower, 6 upper, and 7 shaking recorded from the Kanto district to the Tohoku district. The earthquake generated a huge tsunami that caused catastrophic damage to the Pacific coast of Honshu Island, particularly to Iwate, Miyagi, and Fukushima Prefectures. The resulting tsunami also damaged five K-NET and Hi-net/KiK-net stations in Iwate and Miyagi Prefectures, and the DMC was damaged by the strong motion and the subsequent power outages that lasted for 
a

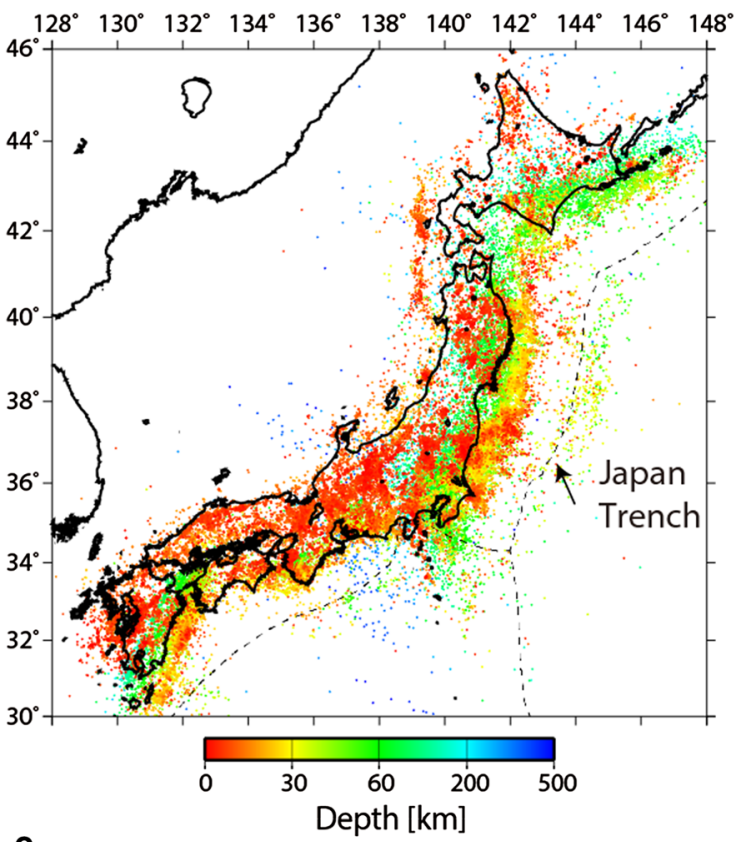

C

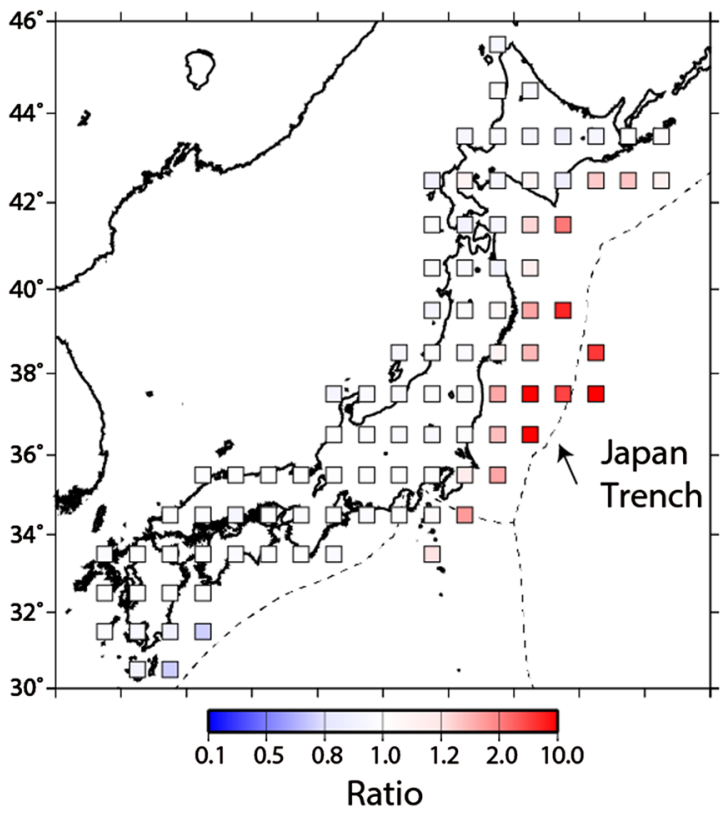

b

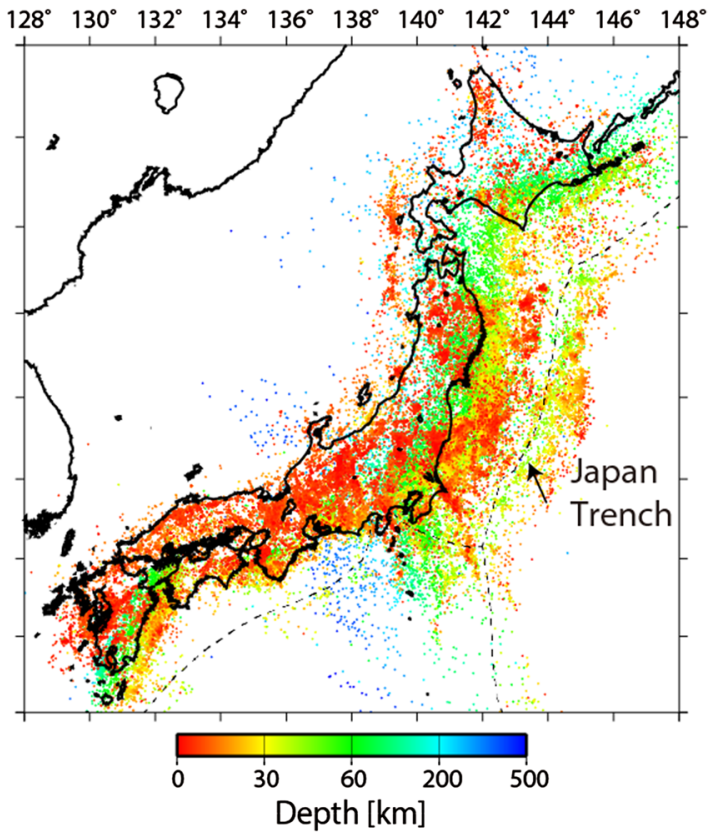

Fig. 11 Distribution of hypocenters estimated from a Dataset 1, $\mathbf{b}$ Dataset 2, and $\mathbf{c}$ the number ratio of events from Dataset 2 to those from Dataset 1. In $\mathbf{a}$ and $\mathbf{b}$, the dots denote estimated hypocenters. The color indicates the depth of the hypocenters. In $\mathbf{c}$, the number ratio was estimated from numbers of earthquakes shallower than $60 \mathrm{~km}$ within each one-degree bin for both datasets using 100 events for both datasets. The evaluated number ratios are plotted as the colored squares in the center locations of these bins. The color used for the number ratio is shown below (c)

almost one day. Despite the damage due to these severe situations, K-NET and KiK-net ultimately succeeded in obtaining strong motion accelerograms at more than 1000 stations covering Japan. The records of two stations that were completely swept away by the tsunami before the data could be collected were lost. The released data consist of accelerograms from 1212 stations, including 19 stations where PGAs of above $1000 \mathrm{~cm} / \mathrm{s} / \mathrm{s}$ were recorded. 


\section{Toward integration of land and seafloor data}

The presence of densely distributed stations directly above seismic activity enables us to detect small earthquakes and constrain the depths of shallow earthquakes. Therefore, the construction of seafloor seismograph networks such as S-net and DONET is expected to improve earthquake detectability and the estimation accuracy of hypocenters in and around these networks.

To examine the detectability improvement, we investigated a number of detected and located events from two different 2019 datasets. One dataset (Dataset 1) includes observations primarily conducted at land stations operated by Hi-net, JMA, universities, and other institutes. The other dataset (Dataset 2) includes S-net and DONET seafloor data in addition to land station data. We analyzed these datasets using a routine $\mathrm{Hi}$ net detection and hypocenter determination system. The distributions of hypocenters $(M \geq 0)$ obtained from these two datasets and their ratios of the number of detected events are shown in Fig. 11a, b, c, respectively. It can be seen that the seismicity shown in Fig. 11b from Dataset 2 is quite similar to that in Fig. 11a from Dataset 1 in the land area. However, in Fig. 11b, there is also a seismically active area along the Japan Trench. According to Fig. 11c, compared to the numbers from Dataset 1 , two to ten times more earthquakes were detected in this area based on Dataset 2. This difference shows the detectability improvement due to the construction of S-net. The most predominant earthquake cluster is distributed around $38^{\circ} \mathrm{N}, 145^{\circ} \mathrm{E}$ (Fig. 11b). In the same area, thrust-type intraplate aftershocks related to the 2011 Tohoku earthquake were reported by Asano et al. (2011) and Obana et al. (2014). The present results obtained from $\mathrm{S}$-net data show that such aftershocks in the vicinity of the Japan Trench are still occurring. The number of detected and located events from Dataset 2 is slightly lower compared to that from Dataset 1 in some areas such as off Kyushu. In such areas, seafloor data and land data may be not simultaneously explained by the assumed velocity structure. In this analysis, the same one-dimensional (1D) velocity structure, which is routinely used for hypocenter determinations for inland Hi-net stations (Obara et al. 2005), was used for Dataset 1 and Dataset 2. Although this velocity model is suitable for an island arc, it is not a best-fit model for an offshore area. Therefore, by revising this velocity model in the future, we may be able to detect many more earthquake locations with improved accuracy.

\section{Discoveries in earth science}

MOWLAS data have contributed to a significant number of discoveries in earth science. Observations taken from above source regions have significant advantages for a deep understanding of phenomena in academia, as well as major impacts on earthquake early warning and tsunami warning. In particular, observations taken directly above offshore earthquakes enable us to detect seismicity and tremors and investigate the focal mechanisms and source processes of regular and slow earthquakes.

High-quality dense data have also contributed to the discovery of new geophysical phenomena. Obara (2002) discovered nonvolcanic tremors in the southwest Japan subduction zone from continuous Hi-net velocity meter seismograms, and Obara et al. (2004) detected SSEs accompanied by tremor episodes from tilt data. In addition, Ito et al. (2007) reported on VLFEs coincident with episodic tremors and SSEs detected from tilt data and F-net data. Many scientific findings related to slow earthquake mechanisms have also been reported (e.g., Shelly et al. 2006, 2007; Ide et al. 2007; Hirose et al. 2010; Obara and Kato 2016). These discoveries have contributed to an improved understanding of the coupling behavior along this subduction zone. Hi-net data obtained at densely distributed stations have enabled the production of highresolution images of the structure in the crust and the upper mantle. The data have also been used for travel time tomography (e.g., Matsubara et al. 2008; Nakajima and Hasegawa 2007; Nishida et al. 2008; Brenguier et al. 2014), analyses of attenuation structures (e.g., Nakajima et al. 2013; Kita et al. 2014), S-wave splitting (e.g., Long and van der Hilst 2005; Nakajima et al. 2006), and inferring conversion properties from receiver functions (e.g., Kawakatsu and Watada 2007; Shiomi et al. 2008). These studies on the structure in the crust and the upper mantle have contributed to the understanding of the seismotectonics of the Japan Islands. Currently, Hi-net data are analyzed alongside S-net and DONET data collected from ocean bottom seismometers, and both land and seafloor data will soon be joined by improved ray coverage along the northeastern Japan arc. This will strongly advance seismotectonics investigations in Japan in the future.

The K-NET/KiK-net data are used internationally because a significant number of extreme ground motions have been observed (e.g., Aoi et al. 2008; Anderson 2010). These data contribute to the development of several ground motion prediction equations (e.g., Kanno et al. 2006; Morikawa and Fujiwara 2013; Dhakal et al. 2015) and serve as the backbone of the national seismic hazard assessment summarized as Japan Seismic Hazard Information Station (J-SHIS) (e.g., Fujiwara et al. 2006). The data have resulted in detailed source rupture processes for the 2003 Tokachi-oki, 2004 Niigata Chuetsu, 2005 Fukuoka, 2007 Chuetsu-oki, 2008 Iwate-Miyagi Nairiku, 2009 Suruga Bay, 2011 Tohoku, 2016 Kumamoto, 2018 
Hokkaido eastern Iburi, and other earthquakes. In related investigations, source inversions are applied to estimates of stress transfer to source regions (e.g., Toda and Stein 2003; Aoi et al. 2010), and site responses are estimated for seismic hazards nationwide (e.g., Kawase and Matsuo 2004; Nozu and Nagao 2005; Morikawa et al. 2008).

The F-net waveform data contribute to the MT analysis of regular earthquakes (e.g., Fukuyama et al. 1998; Kubo et al. 2002), and the detection and understanding of slow earthquakes of the Japan Islands, especially VLFEs, which are characterized by seismic waves with a predominant period range of 10 to $20 \mathrm{~s}$. In the Nankai Trough region, CMTs of shallow VLFEs close to the trench axis (e.g., Ito and Obara 2006; Takemura et al. 2018) and deep VLFEs at the downdip part of the seismogenic zone (e.g., Ito et al. 2007) have been estimated from F-net data. VLFEs off the Pacific coast of Tohoku were detected and located using a matched-filter-based method that was applied to F-net data (Matsuzawa et al. 2015; Nishikawa et al. 2019). For the application to volcanic phenomena following a discovery by Kumagai et al. $(2001,2003)$, the source process of the Kuchinoerabu-jima volcanic eruptions in 2014 and 2015 (Matsuzawa et al. 2016) and the mass movement process in the 2011 deep-seated Akatani landslide (Yamada et al. 2013) were revealed by an inversion analysis using F-net data. This verifies that the broadband waveform data obtained from F-net can help us to understand various crustal activities over wide timescales.

S-net data have successfully captured the entire process of earthquake and tsunami generation directly above offshore source regions, and NIED has released the first example for the 2016 off Fukushima earthquake. Additionally, recent open data from S-net contributed to the discovery of a slow slip along the Japan Trench (e.g., Nishikawa et al. 2019; Tanaka et al. 2019), which strengthens the previous discovery of slow slip detected from land observations (Asano et al. 2008). Furthermore, due to the advanced detection capability of S-net sub-centimeter pressure gauge sensors (e.g., Kubota et al. 2019), the early detection of tsunamis from distant earthquakes, such as those that occur off the coast of Chile, has become possible.

Each month, DONET records several hundred small events with magnitudes larger than one that are included in the seismicity along mostly inactive plate boundaries. The distribution of seismicity is heterogeneous, and three clusters have been identified under Node B of DONET1 (Fig. 6) within a 30-km depth (e.g., Suzuki et al. 2016). According to Wallace et al. (2016), the plate coupling beneath the DONET1 area is weak. DONET is installed on thick sedimentary layers whose P-wave velocities are between 3 and $4 \mathrm{~km} / \mathrm{s}$. These sedimentary layers are lens-shaped and originated due to the accretion of the subducting crust and trough axis turbidites. The accretionary prism amplifies long-period ground motions (e.g., Furumura and Saito 2009; Nakamura et al. 2015; Kubo et al. 2019), and the production process of these is an important unresolved scientific issue. SSEs have been detected by DONET near the Nankai Trough axis (e.g., Nakano et al. 2018; Toh et al. 2016). For example, Nakano et al. (2018) found that shallow VLFEs follow SSEs on the common plate boundary, and Araki et al. (2017) showed that crustal strain moved from north to south just after the 2016 off southeast Mie earthquake $\left(M_{\mathrm{w}} 6.5\right)$ and that SSEs were activated at the shallow plate boundary. Ariyoshi et al. (2012) indicated that shallow SSEs are activated when the locked zone on the plate boundary becomes weak before a rupture. Taken together, these results show that slow slip activity should be monitored. DONET recorded a small tsunami with a height of a few centimeters that was produced by the 2016 off southeast Mie earthquake; micro-tsunamis have also been identified. For the 2014 Chile Iquique earthquake, DONET as well as $\mathrm{S}$-net recorded small tsunami signals with a height of approximately $5 \mathrm{~mm}$.

V-net data on the 2011 Shinmoe-dake eruption of Mt. Kirishima, in which a magmatic eruption occurred in January 2011, indicates that three sub-Plinian eruptions occurred from 26 to 27 January, then changed to lava effusion into the crater. From GNSS observations of V-net, an expansion of the magma chamber located about $7 \mathrm{~km}$ northwest of Shinmoe-dake since the beginning of the installation has been observed. Although crustal movements and seismic activity were not observed before the eruption, the intermittent magma chamber contraction caused by the three sub-Plinian eruptions and the subsequent continuous contraction caused by lava effusion could be identified with a high level of accuracy using V-net tiltmeters (Ueda et al. 2013). From the relationship between the amount of contraction and the eruption, the temporal change of the eruption rate could be estimated with high accuracy, and the relationship with the eruption style was clarified (Kozono et al. 2013). These results show that V-net data contribute to eruption prediction research and volcanic disaster prevention.

Following the initial mission of making fundamental observations, NIED has presented various scientific outcomes using MOWLAS data related to events such as the 2011 Tohoku earthquake (e.g., Asano et al. 2011; Matsubara and Obara 2011; Suzuki et al. 2011; Aoi et al. 2012) and the 2016 Kumamoto earthquake sequence (e.g., Kubo et al. 2016; Sawazaki et al. 2016; Suzuki et al. 2017; Yano and Matsubara 2017). NIED also continuously upgrades the estimates of the depth of the Philippine Sea plate (e.g., Ishida 1992; Shiomi et al. 2004, 2008; Hori 2006). 


\section{Real-time applications}

Real-time data from MOWLAS are used for the mitigation of ongoing earthquakes and tsunamis. The current system operated by JMA issues earthquake early warning within a few seconds after earthquake detection. Then, seismic intensity information, hypocenter and magnitude information, and tsunami warning are, respectively, issued one and half minutes, a few minutes, and about $3 \mathrm{~min}$ after the earthquake occurrence. In this way, the MOWLAS data provided in real time to JMA are utilized for earthquake early warning and tsunami warning, as well as seismic intensity measures and tsunami information.

\section{Real-time applications from land observations}

A recent major innovation in earthquake disaster prevention is the realization of earthquake early warning, which has been made possible by real-time dense observations and excellent algorithms (e.g., Tsukada et al. 2004; Horiuchi et al. 2005). JMA has operated the earthquake early warning system nationwide, except for remote islands, since 2007. This system has started to utilize real-time data from about 1000 stations, including about 200 JMA earthquake versatile observation system stations equipped with multi-function seismic sensors (Harada 2007) and about $800 \mathrm{Hi}$-net stations.

For seismic intensity measurements, data are collected from the seismic intensity meters installed in all municipalities nationwide. The collected seismic intensity data are unified within one and half minutes after the earthquake occurrence, and then immediately provided to the public via broadcast media as well as national and local governments. This contributes to accelerating initial responses and is provided to a wide-area support system for emergency disaster response. This arrangement, which is called the Seismic Intensity Information System, consists of about 4400 stations in total. Of these, about 700 are JMA stations, about 800 are K-NET stations, and about 2900 are local government stations. Seismic intensities are calculated in situ inside seismic intensity meters using the three components of 1-min-long strong motion acceleration waveforms. The resulting seismic intensity is automatically transmitted to each organization, and is unified into nationwide information at JMA. K-NET sensors and JMA seismic intensity meters not only record seismic intensity values, but also collect ground motion waveform data. Most of the seismic intensity meters installed by local governments also have these functions.

Because current technology is capable of delivering real-time information just after the occurrence of an earthquake, real-time ground motion information now plays an important role in society. For this purpose and real-time seismic risk assessments, NIED has researched and developed various real-time strong motion monitoring systems. One important component of this system is low-latency continuous strong motion observations. K-NET02 and all later seismographs used in K-NET and KiK-net are capable of calculating and transmitting several strong motion indices such as real-time seismic intensity, PGA, and PGV continuously. Real-time seismic intensity developed by NIED calculates the JMA seismic intensity continuously, promptly, and accurately. In addition to KiK-net, NIED has started an experimental study to continuously monitor strong ground motion at K-NET stations using best-effort telecommunication service. For example, NIED operates Kyoshin Monitor, which is a real-time ground motion visualization and monitoring system that generates shake maps for uploading to the NIED website (Fig. 12; Aoi et al. 2013; www.kmoni .bosai.go.jp/, Accessed 30 Apr 2020) every second based on the strong motion indices that are continuously calculated and transmitted from K-NET and KiK-net stations. JMA started to use the long-period ground motion levels in 2013 based on 5\%-damped absolute velocity response spectra in the period range of 1.6 to $7.8 \mathrm{~s}$ that are not captured by current seismic intensity measurements. K-NET11 and KiK-net11 seismographs are capable of calculating and transmitting long-period ground motion levels and related indices. NIED has also developed a monitoring system (Aoi et al. 2020a) that provides realtime shake maps of long-period ground motion levels as Long-Period Ground Motion Monitor (Fig. 12).

Previously, JMA tsunami warnings were issued based only on hypocenters and magnitudes obtained from land observations of JMA and Hi-net data without direct tsunami detection. The quantitative tsunami forecast system that was introduced in 1999 (e.g., Nagai 2005) established tsunami heights and arrival times that were calculated in advance using numerical simulations based on hypocenters and magnitudes. These calculations are archived in the form of a tsunami forecast database (Ishigaki 2002), and tsunami warnings are now issued based on the results of database searches. During the $2011 M_{\mathrm{w}} 9.0$ Tohoku earthquake, earthquake early warning was issued $8.6 \mathrm{~s}$ after the earthquake detection. However, the initial magnitude estimate was 7.2, which was increased to 8.1 at $116.8 \mathrm{~s}$ after the mainshock as a final magnitude of earthquake early warning. The manual estimates of hypocenter and magnitude resulted in M7.9 and the initial tsunami warning was issued based on this information within $3 \mathrm{~min}$ of the earthquake. This is why both earthquake early warning and tsunami warning resulted in underestimations. Later, rapid tide increases were observed at GPS buoys operated by the Nationwide Ocean Wave information network for Ports and HArbourS (NOWPHAS; Nagai 2002) including the off Kamaishi buoy located 


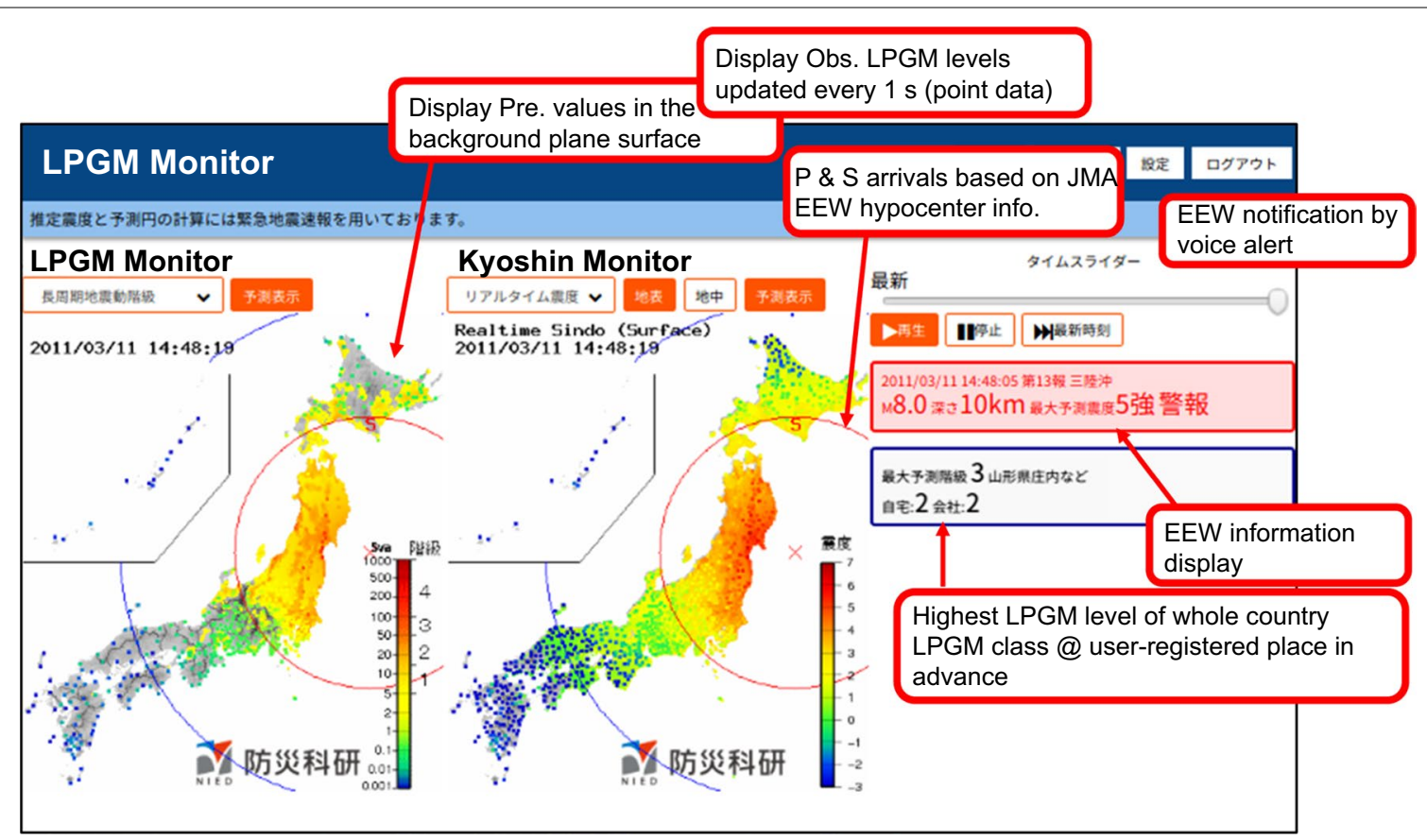

Fig. 12 Long-Period Ground Motion Monitor (left) with the intensity scale for long-period ground motions and Kyoshin Monitor (right) with the JMA seismic intensity scale reproducing the 2011 Tohoku earthquake

about $20 \mathrm{~km}$ away from the coast, and a second tsunami warning was issued 28 min after the mainshock. Cabletype seafloor pressure gauges installed by ERI located further off Kamaishi captured earlier pressure changes. In their post-event analyses, JMA (2012) reported that it would be possible to provide more prompt and accurate tsunami warning updates if seafloor observation data could be combined with more suitable analysis methods and utilized more effectively for onsite operations. A significant lesson learned from the aftermath of the 2011 Tohoku earthquake and tsunami was that the use of land observation data alone is inadequate for providing early warnings of offshore megathrust events. This highlights the importance of real-time earthquake and tsunami observations taken from above offshore source regions.

\section{Real-time applications from land and seafloor observations} From the viewpoint of early warning, earthquakes occurring on land are theoretically associated with unavoidable negative-lead-time zones within a radius of about 20 to $30 \mathrm{~km}$ from the epicenter (Nakamura et al. 2009). Seafloor observations are an extension of observations to unpopulated areas, and obviously have the advantage of providing additional lead time for earthquake early warning and tsunami warning for offshore events. These networks make it possible to directly confirm tsunami generation. Figure 13 shows simulations of the time difference of earthquake and tsunami first arrivals with and without S-net and DONET. For earthquakes, the difference between the arrival times of earthquakes based on the existing stations with and without S-net and DONET is as much as $30 \mathrm{~s}$ for the best case depending on the location of the seismic source. The existing stations used for the simulations are Hi-net, the ETMC system, and the JMA cable-type seafloor observation systems for earthquakes and tsunamis off Tokai/Tonankai. For tsunamis, the time difference between the arrival times of near-field tsunamis based on the existing stations with and without S-net and DONET is as much as $20 \mathrm{~min}$ for the best case depending on the location of the seismic source. The existing stations used for the simulations are tide stations (JMA, GSI, Japan Coast Guard, and local governments), ocean bottom observatories (JMA, JAMSTEC, ERI, and ETMC), and GPS buoys (NOWPHAS). Combining data from S-net and DONET with the existing stations results in increased lead time for earthquake early warning and tsunami warning compared to those produced based on land and onshore observations. Figure 14 shows actual waveforms of S-net seafloor observations and $\mathrm{KiK}$-net land observations for the 20 August 2016 off Fukushima earthquake (Mj 6.4). This earthquake occurred about $170 \mathrm{~km}$ off shore and the S-net observation data detected the earthquake $21.82 \mathrm{~s}$ earlier than the KiK-net stations. 

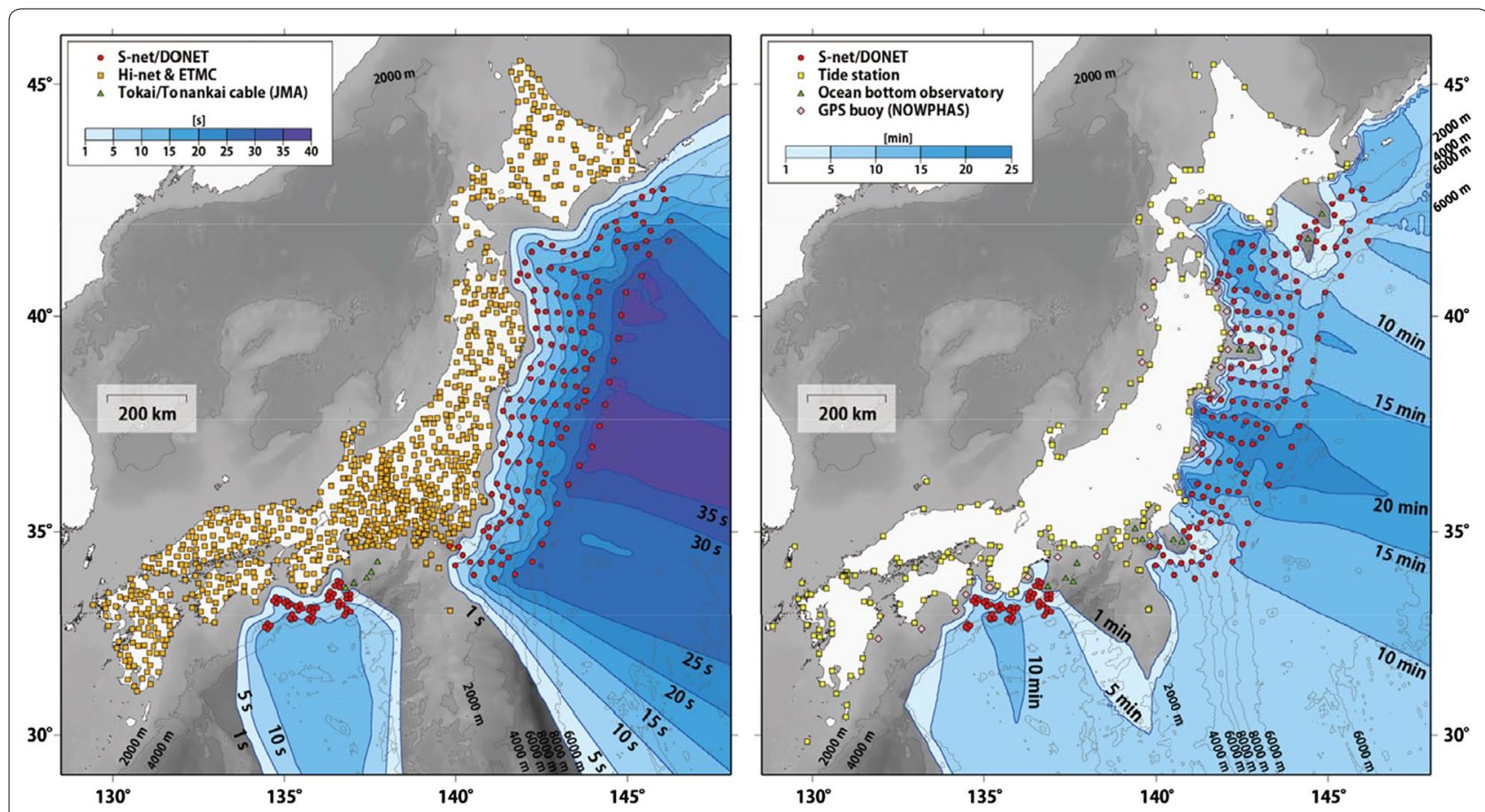

Fig. 13 Maps of simulations of the time difference of earthquake (left, in seconds) and tsunami (right, in minutes) first arrivals with and without S-net and DONET

Using offshore tsunami heights, JMA estimates onshore tsunami heights using Green's theory, which states that such heights are inversely proportional to the water depth, and uses this information when providing offshore tsunami observation alerts. The pressure data of S-net (subsystems S1 to S5) and DONET2 were first used for tsunami information in 2016, and were included for use in S-net (subsystem S6) information in 2017. In addition, the use of S-net pressure data for updating information provided by tsunami warning began in 2019 . For earthquake early warning, two DONET1 stations and $15 \mathrm{KiK}$-net stations, S-net stations of subsystems S1 to S5 and the remaining DONET stations, and the remaining S-net stations were included in 2015, 2019, and 2020, respectively.

Seafloor observations need to overcome different conditions than land observations, particularly because seafloor observatories are normally located on soft sediment layers, which makes it hard to produce firm coupling between the equipment and the seafloor. Nevertheless, using data accumulation, the characteristics of seafloor observations have been investigated and good techniques for properly handling such data have been proposed. For example, the use of the derivative waveforms of pressure can drastically reduce the effects of step noise during strong motions (Kubota et al. 2018), and using only the up-down component when estimating the seismic moment can reduce the equipment rotation effects that often occur during strong motions (Hayashimoto et al. 2019).

\section{Seafloor observations utilization by local governments and private sector}

Additional lead time and detection accuracy improvements have made the JMA earthquake early warning and tsunami warning more effective. They have also contributed to enhancing the alert operations of local governments and the infrastructure of private sectors.

For example, using DONET data, a real-time tsunami prediction system has been adopted by the local governments of Wakayama and Mie Prefectures, including Owase City, as well as by Chubu Electrical Power Co., Inc. and Kagawa University (Takahashi et al. 2017, 2018; Ishibashi et al. 2018). The real-time tsunami warning system forecasts the arrival time, height, and inundation area of tsunamis, along with their maximum depths, based on observed pressure data.

In Japan, high-speed Shinkansen trains operate at speeds that can reach $320 \mathrm{~km} / \mathrm{h}$. It is thus important to reduce speed as soon as possible when large earthquakes occur to avoid derailment and collisions with oncoming trains. As a safety measure, Japan Railways (JR) 


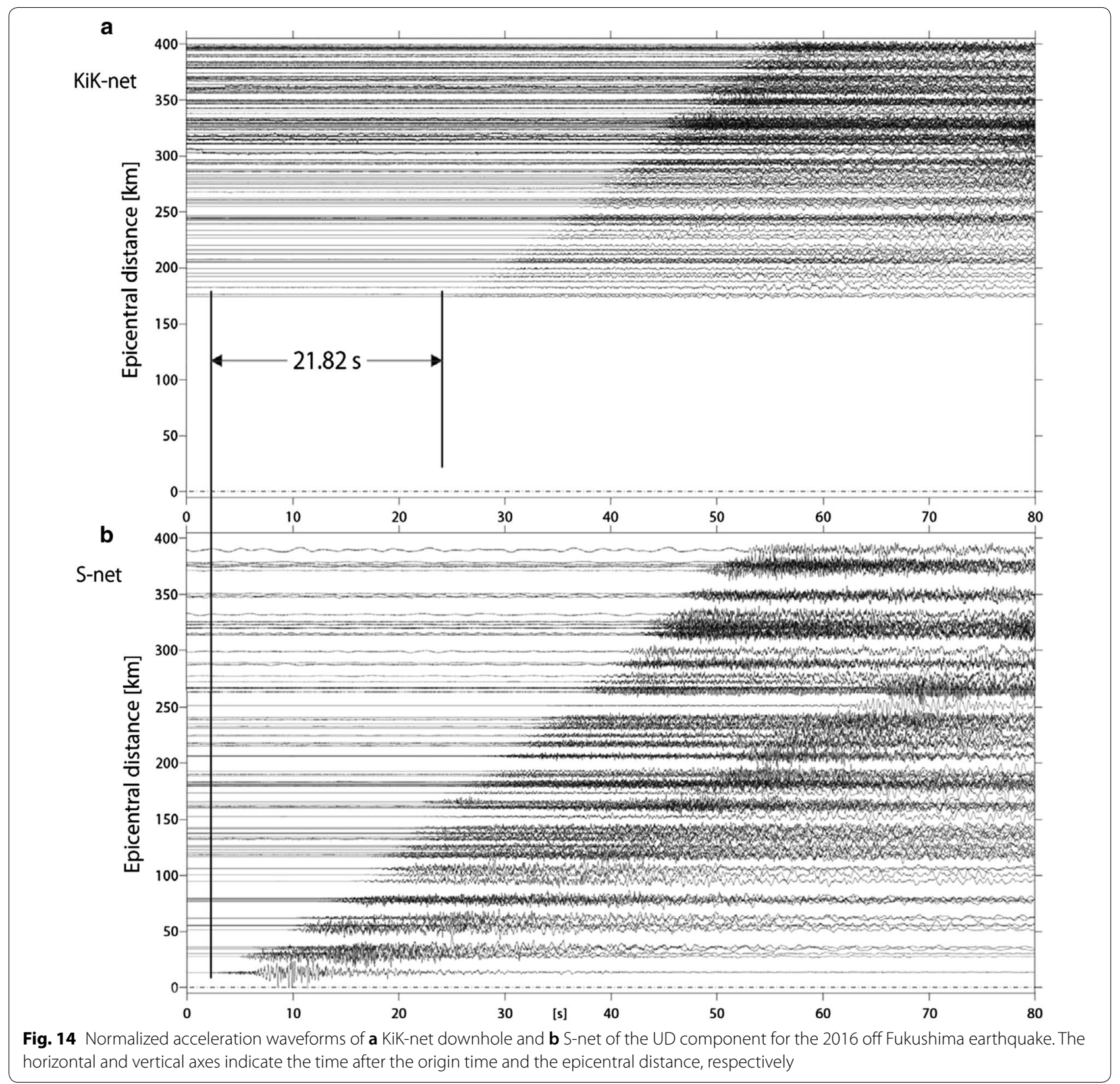

introduced the Urgent Earthquake Detection and Alarm System (UrEDAS) in the early 1990s (Nakamura 1988). UrEDAS issues warning to stop Shinkansen trains when it detects P-wave values from its own seismometers. Furthermore, S-net and DONET data are applied to control Shinkansen trains for disaster prevention of social infrastructure for the private sectors. Based on signed agreements between NIED and three JR companies, NIED provides several indices of acceleration and real-time seismic intensity, and significantly increases lead time to stop Shinkansen trains using an alarm method based on a threshold value being exceeded developed by Korenaga et al. (2019a). The calculations are done in situ at the landing stations of each cable system for S-net and at the NIED DMC for DONET, and then directly transmitted to the JR companies (Korenaga et al. 2019b). Seafloor observatories are installed away from railways, so it is necessary to consider the attenuation that occurs with distance and the site amplification that is related to seafloor stations located on soft sedimentary layers. The alerts issued to stop Shinkansen trains are triggered when the threshold set in advance is exceeded. By using seafloor 
observations, the detection of events that would result in emergency train stoppages can be issued as much as 10 to $30 \mathrm{~s}$ earlier. S-net strong motion data have been used in real time to control Shinkansen trains operated by JR East since 2017 and by JR Central since 2019. DONET strong motion data have been used in real time to control Shinkansen trains operated by JR Central and JR West since 2019. S-net and DONET data play an important role in supporting the national social infrastructure.

\section{Other applications}

To facilitate appropriate initial actions, risk information related to damage as well as hazard information such as seismic intensity data is important. Currently, real-time observation data are used for the rapid estimation of disasters by, for example, Japan Real-time Information System for earthQuake (J-RISQ) (e.g., Nakamura et al. 2013) and Damage Information System for Earthquake on Railway (DISER) (e.g., Yamamoto et al. 2020).

Heavily urbanized areas such as the Tokyo Metropolitan Area, which have large populations and complex urban structures, are considered to suffer more intensely from earthquake disasters, and thus need denser observation networks. In the Tokyo Metropolitan Area, NIED operates a real-time observation network known as the Metropolitan Seismic Observation network (MeSOnet) (Hirata et al. 2009; Kasahara et al. 2009; Sakai and Hirata 2009). Construction of MeSO-net began in 2007 by ERI, Hot Spring Research Institute of Kanagawa Prefecture, and NIED. Operation of the network was transferred to NIED in 2017. This dense network, which consists of about 300 stations emplaced at 2 to $10 \mathrm{~km}$ intervals within the Tokyo Metropolitan Area, records seismic waveforms as well as ground motion index data in real time. Using data from MeSO-net together with other super-dense real-time networks such as SUPerdense REal-time Monitoring of Earthquakes (SUPREME) operated by the Tokyo Gas Co., Ltd. (Shimizu et al. 2001; Nakayama et al. 2004) will make it possible to capture important ground motion characteristics in complex urban basins, as well as to better understand the significant and integrated mechanisms of disasters.

\section{Summary}

As a result of lessons learned from two recent earthquake disasters, MOWLAS was established in November 2017 to integrate the seven NIED observation networks of $\mathrm{Hi}$ net, K-NET, KiK-net, F-net, V-net, S-net, and DONET. The openly available data have resulted in new scientific findings such as the discovery of various kinds of tremors and slow earthquakes, the investigation of source processes, the development of velocity structure models, and direct observations of extreme ground motions.
MOWLAS data serve as information fundamentals that are used in earthquake engineering as well as for seismic, tsunami, and volcano hazard assessments at the national and local government levels for disaster resilience. Real-time data are also used for national-level disaster information of earthquakes, tsunamis, and volcanoes, including earthquake early warning and tsunami warning operated by JMA, and by private sectors. NIED has learned the vast importance of recording and transferring data securely, even under severe conditions such as those during the 2011 Tohoku earthquake and tsunami and the 2016 Kumamoto earthquake. To overcome these issues, MOWLAS is updated with the latest observational technologies for earthquakes, tsunamis, and volcanoes toward improving earth science and disaster resilience.

\section{Supplementary information}

Supplementary information accompanies this paper at https://doi. org/10.1186/s40623-020-01250-x.

Additional file 1: Figure S1. Hi-net station distribution with the NIED DMC and the ETMC system in the Sagami Bay. Figure S2. K-NET and KiKnet station distribution with the NIED DMC, the sub DMC, and the ETMC system in the Sagami Bay. Figure S3. F-net station distribution with the NIED DMC. Figure S4. Offshore station distribution of S-net, DONET, and the ETMC system in the Sagami Bay with the NIED DMC and landing stations. Figure S5. V-net station distribution with the NIED DMC.

\section{Abbreviations}

A/D: Analog-to-digital; AQUA: Accurate and QUick Analysis System for Source Parameters; CCPVE: Coordinating Committee for Prediction of Volcanic Eruption; CMT: Centroid moment tensor; DISER: Damage Information System for Earthquake on Railway; DMC: Data Management Center; DONET: Dense Oceanfloor Network system for Earthquakes and Tsunamis; ETMC: Earthquake and Tsunami Monitoring Cable; F-net: Full Range Seismograph Network of Japan; FPGA: Field-programmable gate array; FREESIA: Fundamental Research on Earthquakes and Earth's Interior Anomaly; FRP: Fiber-reinforced plastic; GEONET: GNSS Earth Observation Network System; GNSS: Global Navigation Satellite System; GPS: Global Positioning System; GSI: Geospatial Information Authority of Japan; HERP: The Headquarters for Earthquake Research Promotion; Hi-net: High Sensitivity Seismograph Network Japan; J-RISQ: Japan Real-time Information System for earthQuake; J-SHIS: Japan Seismic Hazard Information Station; JAMSTEC: Japan Agency for Marine-Earth Science and Technology; JMA: Japan Meteorological Agency; JR: Japan Railways; JUICE: Japan Unified hl-resolution relocated Catalog for Earthquakes; K-NET: Kyoshin Network; KiK-net: Kiban Kyoshin Network; MeSO-net: Metropolitan Seismic Observation network; MEXT: Ministry of Education, Culture, Sports, Science and Technology; MOWLAS: Monitoring of Waves on Land and Seafloor; N-net: Nankai Trough Seafloor Observation Network for Earthquakes and Tsunamis; NIED: National Research Institute for Earth Science and Disaster Resilience; NOWPHAS: Nationwide Ocean Wave information network for Ports and HArbourS; RINEX: Receiver Independent Exchange Format; S-net: Seafloor observation network for earthquakes and tsunamis along the Japan Trench; S/N: Signal-to-noise ratio; SSE: Slow slip event; SUPREME: Super-dense real-time monitoring of earthquakes; TDX: Tokyo Data eXchange; UPS: Uninterruptible power supply; UrEDAS: Urgent Earthquake Detection and Alarm System; V-net: The Fundamental Volcano Observation Network; VLFE: Very-low frequency earthquake.

\section{Acknowledgements}

We thank Takayuki Miyoshi, Azusa Nishizawa, Yoshimitsu Okada, and Wataru Suzuki. We used the Generic Mapping Tools (Wessel and Smith 1998) to draw the figures. 


\section{Authors' contributions}

SA, YA, TKu, TKi, KU, NT, and HU drafted the manuscript. All authors read and approved the final manuscript.

\section{Funding}

Not applicable.

\section{Availability of data and materials (as of the end of 2019)}

NIED Hi-net, National Research Institute for Earth Science and Disaster Resilience, doi: https://doi.org/10.17598/nied.0003. https://www.hinet.bosai.go. jp/? LANG=en

NIED K-NET, KiK-net, National Research Institute for Earth Science and Disaster Resilience, https://doi.org/10.17598/nied.0004. https://www.kyoshin.bosai.go. $\mathrm{jp} /$

NIED F-net, National Research Institute for Earth Science and Disaster Resilience, https://doi.org/10.17598/nied.0005. https://www.fnet.bosai.go.jp/top. php? $\mathrm{LANG}=\mathrm{en}$

NIED V-net, National Research Institute for Earth Science and Disaster Resilience, https://doi.org/10.17598/nied.0006. https://www.vnet.bosai.go.jp/ NIED S-net, National Research Institute for Earth Science and Disaster Resilience, https://doi.org/10.17598/nied.0007. https://www.seafloor.bosai.go.jp/ NIED DONET, National Research Institute for Earth Science and Disaster Resilience, https://doi.org/10.17598/nied.0008. https://www.seafloor.bosai.go.jp/ NIED MOWLAS, National Research Institute for Earth Science and Disaster Resilience, https://doi.org/10.17598/nied.0009. https://www.mowlas.bosai.go. jp/?LANG=en

\section{Competing interests}

The authors declare that they have no competing interests.

Received: 3 May 2020 Accepted: 11 Auqust 2020

Published online: 07 September 2020

\section{References}

Anderson JG (2010) Source and site characteristics of earthquakes that have caused exceptional ground accelerations and velocities. Bull Seismol Soc Am 100:1-36. https://doi.org/10.1785/0120080375

Aoi S, Kunugi T, Fujiwara H (2004) Strong-motion seismograph network operated by NIED: K-NET and KiK-net. J Jpn Assoc Earthq Eng 4(3):65-74. https://doi.org/10.5610/jaee.4.3_65

Aoi S, Kunugi T, Fujiwara H (2008) Trampoline effect in extreme ground motion. Science 322:727-730. https://doi.org/10.1126/science.1163113

Aoi S, Enescu B, Suzuki W, Asano Y, Obara K, Kunugi T, Shiomi K (2010) Stress transfer in the Tokai subduction zone from the 2009 Suruga Bay earthquake in Japan. Nat Geosci 3:496-500. https://doi.org/10.1038/ ngeo885

Aoi S, Kunugi T, Nakamura H, Fujiwara H (2011) Deployment of new strong-motion seismographs of K-NET and KiK-net. Earthq Data Eng Seismol Geotechn Geol Earthq Eng 14:167-186. https://doi. org/10.1007/978-94-007-0152-6_12

Aoi S, Kunugi T, Suzuki W, Morikawa N, Nakamura H, Senna S, Fujiwara H (2012) Strong motion characteristics of the 2011 Tohoku-Oki earthquake. Zisin 64:169-182. https://doi.org/10.4294/zisin.64.169 (in Japanese with English abstract)

Aoi S, Nakamura H, Kunugi T, Suzuki W, Fujiwara H (2013) Combination of 'Kyoshin monitor' and EEW. AOGS 2013, SE29-D3-AM1-P9-001

Aoi S, Kimura T, Kunugi T, Suzuki W, Dhakal Y, Koja N (2020a) Realtime longperiod ground-motion prediction system and experimental demonstration for its practical usage. In: Proc 17th World Conf Earthq Eng Paper No C001140. (in press)

Aoi S, Takeda T, Kunugi T, Uehira K, Shinohara M, Tanada T, Nagata S, Miyoshi T, Takahashi N (2020b) N-net: Nankai Trough Seafloor Observation Network for Earthquakes and Tsunamis. JpGU-AGU Joint Meeting 2020, HDS08-01

Araki E, Saffer DM, Kopf AJ, Wallace LM, Kimura T, Machida Y, Ide S, Davis E, IODP Expedition 365 shipboard scientists (2017) Recurring and triggered slow-slip events near the trench at the Nankai Trough subduction megathrust. Science 356:1157-1160. https://doi.org/10.1126/scien ce.aan3120
Ariyoshi K, Matsuzawa T, Ampuero JP, Nakata R, Hori T, Kaneda Y, Hino R, Hasegawa A (2012) Migration process of very low-frequency events based on a chain-reaction model and its application to the detection of preseismic slip for megathrust earthquakes. Earth Planet Space 64:693-702. https://doi.org/10.5047/eps.2010.09.003

Asano Y, Obara K, Ito Y (2008) Spatiotemporal distribution of very-low frequency earthquakes in Tokachi-oki near the junction of the Kuril and Japan trenches revealed by using array signal processing. Earth Planets Space 60:871-875. https://doi.org/10.1186/BF03352839

Asano Y, Takeda T, Yukutake Y, Miyoshi T, Obara K, Kasahara K (2010) Seismic velocity structure and seismicity along and around the Itoigawa-Shizuoka Tectonic Line active fault system inferred from data observed at densely distributed stations. Res Rep NIED 77:31-47 (in Japanese with English abstract)

Asano Y, Saito T, Ito Y, Shiomi K, Hirose H, Matsumoto T, Aoi S, Hori S, Sekiguchi $S$ (2011) Spatial distribution and focal mechanisms of aftershocks of the 2011 off the Pacific coast of Tohoku Earthquake. Earth Planets Space 63:669-673. https://doi.org/10.5047/eps.2011.06.016

Brenguier F, Campillo M, Takeda T, Aoki Y, Shapiro NM, Briand X, Emoto K, Miyake $\mathrm{H}$ (2014) Mapping pressurized volcanic fluids from induced crustal seismic velocity drops. Science 345:80-82. https://doi. org/10.1126/science.1254073

Dhakal YP, Suzuki W, Kunugi T, Aoi S (2015) Ground motion prediction equations for absolute velocity response spectra (1-10 s) in Japan for earthquake early warning. J Jpn Assoc Earthq Eng 15(6):91-111. https:// doi.org/10.5610/jaee.15.6_91

Dreger DS, Helmberger DV (1993) Determination of source parameters at regional distances with three-component sparse network data. J Geophys Res 98:8107-8125. https://doi.org/10.1029/93JB00023

Eguchi T, Fujinawa Y, Fujita E, Iwasaki S, Watanabe I, Fujiwara H (1998) A realtime observation network of ocean-bottom-seismometers deployed at the Sagami trough subduction zone, central Japan. Mar Geophys Res 20:73-94. https://doi.org/10.1023/A:1004334021329

Fujiwara H, Kawai S, Aoi S, Ishii T, Okumura T, Hayakawa Y, Morikawa N, Senna S, Kobayashi K, Hao K (2006) Japan Seismic Hazard Information Station, J-SHIS. In: Proc 4th Int Conf Earthq Eng 274

Fujiwara H, Kunugi T, Adachi S, Aoi S, Morikawa N (2007) New K-NET: development of real-time system for strong-motion observation. J Jpn Assoc Earthq Eng 7(2):2-16. https://doi.org/10.5610/jaee.7.2_2

Fukuyama E, Ishida M, Hori S, Sekiguchi S, Watada S (1996) Broadband seismic observation conducted under the FREESIA project. Rep Natl Res Inst Earth Sci Disaster Prev 57:23-31 (in Japanese with English abstract)

Fukuyama E, Ishida M, Dreger DS, Kawai H (1998) Automated seismic moment tensor determination by using on-line broadband seismic waveforms. Zisin 51:149-156. https://doi.org/10.4294/zisin1948.51.1_149 (in Japanese with English abstract)

Furumura T, Saito T (2009) Integrated ground motion and tsunami simulation for the 1944 Tonankai earthquake using high-performance supercomputers. J Disaster Res 4:118-126. https://doi.org/10.20965/jdr.2009. p0118

Hamada K, Ohtake M, Okada Y, Matsumura S, Yamamizu F, Sato H, Imoto M, Tatsukawa M, Ohkubo T, Yamamoto E, Ishida M, Kasahara K, Katsuyama Y, Takahashi H (1982) Kanto-Tokai Observation Network of crustal activities-National Research Center for Disaster Prevention. Zisin 35:401-426. https://doi.org/10.4294/zisin1948.35.3_401 (in Japanese with English abstract)

Hamamatsu O (1966) Historical table of seismographs for routine observations in JMA network. Zisin 19:286-305. https://doi.org/10.4294/zisin 1948.19.4_286 (in Japanese with English abstract)

Harada S (2007) Earthquake versatile observation system. Quart I Seismol 70:73-81 (in Japanese)

Hayashimoto N, Nakamura T, Hoshiba M (2019) A technique for estimating the UD-component displacement magnitude for earthquake early warnings that can be applied to various seismic networks including ocean bottom seismographs. Q J Seismol 83:1-10 (in Japanese with English abstract)

Hirata N, Sakai S, Sato H, Satake K, Koketsu K (2009) An outline of the Special Project for Earthquake Disaster Mitigation in the Tokyo Metropolitan Area—subproject l: characterization of the plate structure and source faults in and around the Tokyo Metropolitan area. Bull Earthq Res Inst Univ Tokyo 84:41-56 (in Japanese with English abstract) 
Hirose H, Asano Y, Obara K, Kimura T, Matsuzawa T, Tanaka S, Maeda T (2010) Slow earthquakes linked along dip in the Nankai subduction zone. Science 330:1502. https://doi.org/10.1126/science.1197102

Hori S (2006) Seismic activity associated with the subducting motion of the Philippine Sea plate beneath the Kanto district, Japan. Tectonophysics 417:85-100. https://doi.org/10.1016/j.tecto.2005.08.027

Hori T (2016) Mechanisms of separation of rupture area and variation in time interval and size of great earthquakes along the Nankai Trough, southwest Japan. J Earth Simulator 5:8-19. https://doi.org/10.32131/jes.5.8

Horiuchi S, Negishi H, Abe K, Kamimura A, Fujinawa Y (2005) An automatic processing system for broadcasting earthquake alarms. Bull Seismol Soc Am 95:708-718. https://doi.org/10.1785/0120030133

Ide S, Beroza GC, Shelly DR, Uchide T (2007) A scaling law for slow earthquakes. Nature 447:76-79. https://doi.org/10.1038/nature05780

Ishibashi M, Baba T, Takahashi N, Imai K (2018) Social implementation of tsunami prediction system on Wakayama by using DONET. J Jpn Soc Nat Disaster Sci 37:125-142. https://doi.org/10.24762/jndsj.37.1_125

Ishida M (1992) Geometry and relative motion of the Philippine Sea Plate and Pacific Plate beneath the Kanto-Tokai District, Japan. J Geophys Res 97:489-513. https://doi.org/10.1029/91JB02567

Ishigaki Y (2002) JMA tsunami observation and tsunami forecast database. Quart J Seismol 65:145-151 (in Japanese)

Ito Y, Obara K (2006) Dynamic deformation of the accretionary prism excites very low frequency earthquakes. Geophys Res Lett 33:L02311. https:// doi.org/10.1029/2005GL025270

Ito Y, Obara K, Shiomi K, Sekine S, Hirose H (2007) Slow earthquakes coincident with episodic tremors and slow slip events. Science 315:503-506. https ://doi.org/10.1126/science.1134454

Japan Meteorological Agency (2012) Report on The 2011 off the Pacific coast of Tohoku Earthquake. Tech Rep Japan Meteorological Agency 133:1-479 (in Japanese with English abstract)

Kanazawa T, Uehira K, Mochizuki M, Shinbo T, Fujimoto H, Noguchi S, Kunugi T, Shiomi K, Aoi S, Matsumoto T, Sekiguchi S, Okada Y (2016) S-net project, cabled observation network for earthquakes and tsunamis. SubOptic 2016, WE2B-3

Kaneda Y, Kawaguchi K, Araki E, Matsumoto H, Nakamura T, Kamiya S, Ariyoshi K, Hori T, Baba T, Takahashi N (2015) Development and application of an advanced ocean floor network system for megathrust earthquakes and tsunamis. Seafloor Observ. https://doi.org/10.1007/978-3-642-11374 -1 -25

Kanno T, Narita A, Morikawa N, Fujiwara H, Fukushima Y (2006) A new attenuation relation for strong ground motion in Japan based on recorded data. Bull Seism Soc Am 96:879-897. https://doi.org/10.1785/01200 50138

Kasahara K, Sakai S, Morita Y, Hirata N, Tsuruoka H, Nakagawa S, Nanjo K, Obara K (2009) Development of the Metropolitan Seismic Observation network (MeSO-net) for detection of mega-thrust beneath Tokyo Metropolitan Area. Bull Earthq Res Inst Univ Tokyo 84:71-88

Kawaguchi K, Araki E, Kaneda Y (2011) Establishment for a method for realtime and long-term seafloor monitoring. J Adv Mar Sci Technol Soc 17:125-135. https://doi.org/10.14928/amstec.17.2_125 (in Japanese with English abstract)

Kawaguchi K, Kaneko S, Nishida T, Komine T (2015) Construction of the DONET real-time seafloor observatory for earthquakes and tsunami monitoring. Seafloor Observ. https://doi.org/10.1007/978-3-642-11374-1_10

Kawakatsu H, Watada S (2007) Seismic evidence for deep water transportation in the mantle. Science 316:1468-1471

Kawase H, Matsuo H (2004) Amplification characteristics of K-NET, KiK-NET, and JMA shindokei network sites based on the spectral inversion technique. In: Proc 13th World Conf Earthq Eng, Paper No 454

Kimura T, Murakami H, Matsumoto T (2015) Systematic monitoring of instrumentation health in high-density broadband seismic networks. Earth Planets Space 67:55. https://doi.org/10.1186/s40623-015-0226-y

Kimura H, Kimura T, Asano Y, Kunugi T, Aoi S (2020) An improved rapid-source parameter determination system (AQUA) for giant earthquakes. IEEE Syst J. https://doi.org/10.1109/JSYST.2020.2983430

Kinoshita S (1998) Kyoshin Net (K-NET). Seismol Res Lett 69:309-332. https:// doi.org/10.1785/gssrl.69.4.309

Kinoshita S (2003) Local event seismograms. Tech Note Natl Res Inst Earth Sci Disas Res 204:1-190
Kita S, Nakajima J, Hasegawa A, Okada T, Katsumata K, Asano Y, Kimura T (2014) Detailed seismic attenuation structure beneath Hokkaido, northeastern Japan: arc-arc collision process, arc magmatism and seismotectonics. J Geophys Res 119:6486-6511. https://doi.org/10.1002/2014JB01 1099

Korenaga M, Yamamoto S, Iwata N, Noda S, Aoi S (2019a) New approaches to improving the immediacy and the accuracy of an earthquake early warning for railways. In: Proc 12th World Congress Railway Res

Korenaga M, Yamamoto S, Noda S, Aoi S (2019b) Earthquake early warning using ocean bottom seismic data for railways. Q Rep RTRI 60:134-149. https://doi.org/10.2219/rtriqr.60.2_134

Kozono T, Ueda H, Ozawa T, Koyaguchi T, Fujita E, Tomiya A, Suzuki YJ (2013) Magma discharge variations during the 2011 eruptions of Shinmoedake volcano, Japan, revealed by geodetic and satellite observations. Bull Volcanol 75:695. https://doi.org/10.1007/s00445-013-0695-4

Kubo A, Fukuyama E, Kawai H, Nomura K (2002) NIED seismic moment tensor catalogue for regional earthquakes around Japan: quality test and application. Tectonophysics 356:23-48. https://doi.org/10.1016/S0040 -1951(02)00375-X

Kubo H, Suzuki W, Aoi S, Sekiguchi H (2016) Source rupture processes of the 2016 Kumamoto, Japan, earthquakes estimated from strong motion waveforms. Earth Planets Space 68:161. https://doi.org/10.1186/s4062 3-016-0536-8

Kubo H, Nakamura T, Suzuki W, Dhakal YP, Kimura T, Kunugi T, Takahashi N, Aoi S (2019) Ground-motion characteristics and nonlinear soil response observed by DONET1 seafloor observation network during the 2016 southeast off-Mie, Japan, earthquake. Bull Seismol Soc Am 109:976986. https://doi.org/10.1785/0120170296

Kubota T, Suzuki W, Nakamura T, Chikasada NY, Aoi S, Takahashi N, Hino R (2018) Tsunami source inversion using time-derivative waveform of offshore pressure records to reduce the effects of non-tsunami components. Geophys J Int 215:1200-1214. https://doi.org/10.1093/ gji/ggy345

Kubota T, Saito T, Suzuki W (2019) Millimeter-scale tsunami detected by a wide and dense observation array in the deep ocean: fault modeling of an $M_{\mathrm{w}} 6.0$ interplate earthquake off Sanriku, NE Japan. Geophys Res Lett 47:e2019GL085842. https://doi.org/10.1029/2019GL085842

Kumagai H, Ohminato T, Nakano M, Ooi M, Kubo A, Inoue H, Oikawa J (2001) Very-long-period seismic signals and the caldera formation at Miyake Island, Japan. Science 293:687-690. https://doi.org/10.1126/scien ce.1062136

Kumagai H, Miyakawa K, Negishi H, Inoue H, Obara K, Suetsugu D (2003) Magmatic dike resonances inferred from very-long-period seismic signals. Science 299:2058-2061. https://doi.org/10.1126/science.1081195

Kunugi T, Aoi S, Nakamura H, Fujiwara H, Morikawa N (2008) A real-time processing of seismic intensity. Zisin 60:243-252. https://doi.org/10.4294/ zisin.60.243 (in Japanese with English abstract)

Kunugi T, Aoi S, Fujiwara H (2009) Strong-motion observation in Japan-History and perspective. Zisin 61:S19-S34. https://doi.org/10.4294/zisin.61.19 (in Japanese with English abstract)

Kunugi T, Aoi S, Nakamura H, Suzuki W, Morikawa N, Fujiwara H (2013) An improved approximating filter for real-time calculation of seismic intensity. Zisin 65:223-230. https://doi.org/10.4294/zisin.65.223 (in Japanese with English abstract)

Long MD, van der Hilst RD (2005) Estimating shear-wave splitting parameters from broadband recordings in Japan: a comparison of three methods. Bull Seismol Soc Am 95:1346-1358. https://doi.org/10.1785/01200 40107

Matsubara M, Obara K (2011) The 2011 Off the Pacific Coast of Tohoku earthquake related to a strong velocity gradient with the Pacific plate. Earth Planets Space 63:663-667. https://doi.org/10.5047/eps.2011.05.018

Matsubara M, Obara K, Kasahara K (2008) Three-dimensional P- and S-wave velocity structures beneath Japan Islands obtained by high-density seismic stations by seismic tomography. Techtonophysics 454:86-103. https://doi.org/10.1016/j.tecto.2008.04.016

Matsumoto T, Hori S, Matsubayashi H (2009) Broadband seismic observation-NIED F-net. Zisin 61:S9-S18. https://doi.org/10.4294/zisin.61.9 (in Japanese with English abstract)

Matsumura M, Ito Y, Kimura H, Obara K, Sekiguchi S, Hori S, Kasahara K (2006) Development of Accurate and Quick Analysis system for source parameters (AQUA). Zisin 59:167-184. https://doi.org/10.4294/zisin.59.167 (in Japanese with English abstract) 
Matsuzawa T, Asano Y, Obara K (2015) Very low frequency earthquakes off the Pacific coast of Tohoku, Japan. Geophys Res Lett 42:4318-4325. https:// doi.org/10.1002/2015GL063959

Matsuzawa T, Matsumoto T, Tanada T (2016) Seismic inversion analysis of the 2014 and 2015 Kuchinoerabujima volcanic eruptions, using F-net broadband seismometers. J Nat Disaster Sci 37:91-103. https://doi. org/10.1785/012003001

McNamara DE, Buland RP (2004) Ambient noise levels in the continental United States. Bull Seismol Soc Am 94:1517-1527. https://doi. org/10.1785/012003001

Mochizuki M, Kanazawa T, Uehira K, Shimbo T, Shiomi K, Kunugi T, Aoi S, Matsumoto T, Sekiguchi S, Yamamoto N, Takahashi N, Shinohara M, Yamada T (2016) S-net project: Construction of large scale seafloor observatory network for tsunamis and earthquakes in Japan. AGU Fall Meeting, NH43B-1840

Morikawa N, Fujiwara H (2013) A new ground motion prediction equation for Japan applicable up to M9 mega-earthquake. J Disaster Res 8:878-888. https://doi.org/10.20965/jdr.2013.p0878

Morikawa N, Kanno T, Narita A, Fujiwara H, Okumura T, FukushimaY Guerpinar A (2008) Strong motion uncertainty determined from observed records by dense network in Japan. J Seismol 12:529-546. https://doi. org/10.1007/s10950-008-9106-2

Nagai T (2002) Long term statistic report on Nationwide Ocean Wave information network for Ports and HArbourS (NOWPHAS 1970-1999). Tech Note Port Airport Res Inst 1035 (in Japanese with English abstract)

Nagai A (2005) Tsunami forecast and observation system in Japan. J Jpn Soc Prec Eng 71:1344-1349. https://doi.org/10.2493/jjspe.71.1344 (in Japanese)

Nakajima J, Hasegawa A (2007) Subduction of the Philippine Sea slab beneath southwestern Japan: slab geometry and its relationship to arc magmatism. J Geophys Res 112:B08306. https://doi.org/10.1029/2006JB004770

Nakajima J, Shimizu J, Hori S, Hasegawa A (2006) Shear-wave splitting beneath the southwestern Kurile arc and northeastern Japan arc: a new insight into mantle return flow. Geophys Res Lett 33:L05305. https://doi. org/10.1002/10.1029/2005GL025023

Nakajima J, Hada S, Hayami E, Uchida N, Hasegawa A, Yoshioka S, Matsuzawa T, Umino N (2013) Seismic attenuation beneath northeastern Japan: constraints on mantle dynamics and arc magmatism. J Geophys Res 118:5838-5855. https://doi.org/10.1002/20013JB010388

Nakamura Y (1988) On the Urgent Earthquake Detection and Alarm System (UrEDAS). In: Proc 9th World Conf Earthq Eng VIl:673-678

Nakamura H, Horiuchi S, Wu C, Yamamoto S, Rydelek PA (2009) Evaluation of the real-time earthquake information system in Japan. Geophys Res Lett 36:L00B01. https://doi.org/10.1029/2008GL036470

Nakamura H, Aoi S, Kunugi T, Suzuki W, Fujiwara H (2013) Prototype of a realtime system for earthquake damage estimation in Japan. J Disaster Res 8:981-989. https://doi.org/10.20965/jdr.2013.p0981

Nakamura T, Takenaka H, Okamoto T, Ohori M, Tsuboi S (2015) Long-period ocean-bottom motions in the source areas of large subduction earthquakes. Sci Rep 5:16648. https://doi.org/10.1038/srep16648

Nakano M, Hori T, Araki E, Kodaira S, Ide S (2018) Shallow very-low-frequency earthquakes accompany slow slip events in the Nankai subduction zone. Nat Commun 9:984. https://doi.org/10.1038/s41467-018-03431-5

Nakayama W, Shimizu Y, Koganemaru K (2004) Development of super dense realtime disaster mitigation system for urban gas supply network. J Jpn Assoc Earthq Eng 4(3):124-127. https://doi.org/10.5610/jaee.4.3_124

National Research Institute for Earth Science and Disaster Resilience (2019a) NIED Hi-net. https://doi.org/10.17598/nied.0003

National Research Institute for Earth Science and Disaster Resilience (2019b) NIED K-NET, KiK-net. https://doi.org/10.17598/nied.0004

National Research Institute for Earth Science and Disaster Resilience (2019c) NIED F-net. https://doi.org/10.17598/nied.0005

National Research Institute for Earth Science and Disaster Resilience (2019d) NIED V-net. https://doi.org/10.17598/nied.0006

National Research Institute for Earth Science and Disaster Resilience (2019e) NIED S-net. https://doi.org/10.17598/nied.0007

National Research Institute for Earth Science and Disaster Resilience (2019f) NIED DONET. https://doi.org/10.17598/nied.0008

National Research Institute for Earth Science and Disaster Resilience (2019g) NIED MOWLAS. https://doi.org/10.17598/nied.0009
Nishida K, Kawakatsu H, Obara K (2008) Three-dimensional crustal S-wave velocity structure in Japan using microseismic data recorded by Hi-net tiltmeters. J Geophys Res 113:B10302. https://doi.org/10.1029/2007J B005395

Nishikawa T, Matsuzawa T, Ohta K, Uchida N, Nishimura T, Ide S (2019) The slow earthquake spectrum in the Japan Trench illuminated by the S-net seafloor observatories. Science 365:808-813. https://doi.org/10.1126/ science.aax 5618

Nozu A, Nagao T (2005) Site amplification factors for strong-motion sites in Japan based on spectral inversion technique. Tech Note Port Airport Res Inst 1112 (in Japanese with English abstract)

Obana K, Kodaira S, Nakamura Y, Sato T, Fujie G, Takahashi T, Tamamoto Y (2014) Aftershocks of the December 7, 2012 intraplate doublet near the Japan Trench axis. Earth Planets Space 66:24. https://doi. org/10.1186/1880-5981-66-24

Obara K (2002) Nonvolcanic deep tremor associated with subduction in southwest Japan. Science 296:1679-1681. https://doi.org/10.1126/ science. 1070378

Obara K, Kato A (2016) Connecting slow earthquakes to huge earthquakes. Science 353:253-257. https://doi.org/10.1126/science.aaf1512

Obara K, Hirose H, Yamamizu F, Kasahara K (2004) Episodic slow slip events accompanied by non-volcanic tremors in southwest Japan subduction zone. Geophys Res Lett 31:L23602. https://doi.org/10.1029/2004GL0208 48

Obara K, Kasahara K, Hori S, Okada Y (2005) A densely distributed highsensitivity seismograph network in Japan: Hi-net by National Research Institute for Earth Science and Disaster Prevention. Rev Sci Instrum 76:021301-1-021301-12. https://doi.org/10.1063/1.1854197

Okada Y (1984) First results from Japanese network for earthquake prediction. Nature 312:500-501. https://doi.org/10.1038/312500a0

Okada Y (1985) Surface deformation due to shear and tensile faults in a halfspace. Bull Seismol Soc Am 75:1135-1154

Okada Y, Yamamoto E (1991) Dyke intrusion model for the 1989 seismovolcanic activity off Ito, central Japan. J Geophys Res 96:10361-10376. https://doi.org/10.1029/91JB00427

Okada Y, Matsumura S, Noguchi S (2000) Performance of the Kanto-Tokai observation network for crustal observation-summary of observational results from the special research project"Research on Crustal Activities in the Kanto-Tokai District" (Part 1)-. Tech Note Natl Res Inst Earth Sci Disas Prev 208 (in Japanese with English abstract)

Okada Y, Kasahara K, Hori S, Obara K, Sekiguchi S, Fujiwara H, Yamamoto A (2004) Recent progress of seismic observation networks in Japan-Hinet, F-net, K-NET and KiK-net. Earth Planets Space 56:15-28. https://doi. org/10.1186/BF03353076

Sagiya T (2004) A decade of GEONET: 1994-2003—-the continuous GPS observation in Japan and its impact on earthquake studies. Earth Planets Space 56:29-41. https://doi.org/10.1186/BF03353077

Sakai S, Hirata N (2009) Distribution of the Metropolitan Seismic Observation network. Bull Earthq Res Inst Univ Tokyo 84:57-69

Sato H, Takahashi H, Yamamoto E, Fukuo N, Uehara M, Terasawa Y (1980) Development of the crustal tilt observation method using borehole-type tiltmeters. Zisin 33:343-368. https://doi.org/10.4294/zisin1948.33.3_343

Sawazaki K, Nakahara H, Shiomi K (2016) Preliminary estimation of highfrequency $(4-20 \mathrm{~Hz})$ energy released from the 2016 Kumamoto, Japan, earthquake sequence. Earth Planets Space 68:183. https://doi. org/10.1186/s40623-016-0557-3

Shelly DR, Beroza GC, Ide S, Nakamula S (2006) Low-frequency earthquakes in Shikoku, Japan and their relationship to episodic tremor and slip. Nature 442:188-191. https://doi.org/10.1038/nature04931

Shelly DR, Beroza GC, Ide S (2007) Non-volcanic tremor and low-frequency earthquake swarms. Nature 446:305-307. https://doi.org/10.1038/natur e05666

Shimada S, Fujinawa Y, Sekiguchi S, Ohmi S, Eguchi T, Okada Y (1990) Detection of a volcanic fracture opening in Japan using Global Positioning System measurements. Nature 343:631-633. https://doi.org/10.1038/343631a0

Shimizu Y, Koganemaru K, Nakayama W, Yamazaki F (2001) Development of Super-dense Real-time Monitoring of Earthquakes (SUPREME). In: Proc JSCE Earthq Eng Symp 26:1285-1288. https://doi.org/10.11532/proee 1997.26.1285. (in Japanese)

Shiomi K, Sato H, Obara K, Ohtake M (2004) Configuration of subducting Philippine Sea plate beneath southwest Japan revealed from receiver 
function analysis based on the multivariate autoregressive model. J Geophys Res 109:B04308. https://doi.org/10.1029/2003JB002774

Shiomi K, Obara K, Kasahara K (2005) Amplitude saturation of the NIED Hi-net waveforms and simple criteria for recognition. Zisin 57:451-461. https:// doi.org/10.4294/zisin1948.57.4_451 (in Japanese)

Shiomi K, Matsubara M, Ito Y, Obara K (2008) Simple relationship between seismic activity along Philippine Sea slab and geometry of oceanic Moho beneath southwest Japan. Geophys J Int 173:1018-1029. https:// doi.org/10.1111/j.1365-246X.2008.03786.x

Shiomi K, Obara K, Haryu Y, Matsumura M (2009) Construction of NIED High Sensitivity Seismograph Network (Hi-net) and its contribution. Zisin 61:S1-S7. https://doi.org/10.4294/zisin.61.1 (in Japanese with English abstract)

Strong-Motion Earthquake Observation Council (1988) Basic plan for nationwide deployment of strong motion seismographs, National Research Center for Disaster Prevention p 45

Suzuki W, Aoi S, Sekiguchi H, Kunugi T (2011) Rupture process of the 2011 Tohoku-Oki mega-thrust earthquake (M9.0) inverted from strong-motion data. Geophys Res Lett 38:LO0G16. https://doi. org/10.1029/2011GL049136

Suzuki K, Nakano M, Takahashi N, Hori T, Kamiya S, Araki E, Nakata R, Kaneda Y (2016) Synchronous changes in the seismicity rate and ocean-bottom hydrostatic pressures along the Nankai trough: a possible slow slip event detected by the Dense Oceanfloor Network system for Earthquakes and Tsunamis (DONET). Tectonophysics 680:90-98. https://doi. org/10.1016/j.tecto.2016.05.012

Suzuki W, Aoi S, Kunugi T, Kubo H, Morikawa N, Nakamura H, Kimura T, Fujiwara $H$ (2017) Strong motions observed by K-NET and KiK-net during the 2016 Kumamoto earthquake sequence. Earth Planets Space 69:19. https://doi.org/10.1186/s40623-017-0604-8

Takahashi H (1982) The deep borehole observatories and their contribution for revealing the characteristics of microearthquake activity in the Kanto district. Rep Natl Res Cent Disaster Prev 28:1-104 (in Japanese with English abstract)

Takahashi N, Imai K, Ishibashi M, Sueki K, Obayashi R, Tanabe T, Tamazawa F, Baba T, Kaneda Y (2017) Real-time tsunami prediction system using DONET. J Disaster Res 12:766-774. https://doi.org/10.20965/jdr.2017. p0766

Takahashi N, Imai K, Sueki K, Obayashi R, Ishibashi M, Tanabe T, Baba T, Kaneda Y (2018) Real-time tsunami prediction system based on seafloor observatory data applied to the inland sea, Japan. Mar Tech Soc J 52:120-127. https://doi.org/10.4031/MTSJ.52.3.12

Takemura S, Matsuzawa T, Kimura T, Tonegawa T, Shiomi K (2018) Centroid moment tensor inversion of shallow very low frequency earthquakes off the Kii Peninsula, Japan, using a three-dimensional velocity structure model. Geophys Res Lett 45:6450-6458. https://doi.org/10.1029/2018G L078455

Tanada T, Ueda H, Nagai M, Ukawa M (2017) NIED's V-net, the fundamental volcano observation network in Japan. J Disaster Res 12:926-931. https ://doi.org/10.20965/jdr.2017.p0926

Tanaka S, Matsuzawa T, Asano Y (2019) Shallow low-frequency tremor in the northern Japan Trench subduction zone. Geophys Res Lett 46:52175224. https://doi.org/10.1029/2019GL082817

The Headquarters for Earthquake Research Promotion (1997) Fundamental earthquake survey and observation plans (August 29, 1997) (In Japanese). https://www.jishin.go.jp/main/w_060_f-e.htm. Accessed 30 Apr 2020

The Headquarters for Earthquake Research Promotion (2011) The 2011 off the Pacific Coast of Tohoku Earthquake (March 11, 2011) https://www.jishi n.go.jp/main/chousa/11 mar_sanriku-oki/index-e.htm. Accessed 30 Apr 2020

The Headquarters for Earthquake Research Promotion (2015) Long-term evaluation of the Itoigawa-Shizuoka Tectonic Line active fault system (second report) (April 24, 2015). https://www.jishin.go.jp/main/chousa/ katsudansou_pdf/41_42_44_itoigawa-shizuoka_2.pdf. Accessed 30 Apr 2020 (In Japanese)

Toda S, Stein R (2003) Toggling of seismicity by the 1997 Kagoshima earthquake couplet: a demonstration of time-dependent stress transfer. J Geophys Res 108:2567. https://doi.org/10.1029/2003JB002527

Toh A, Obana K, Araki E (2016) Distribution of very low frequency earthquakes in the Nankai accretionary prism influenced by a subducting-ridge.
Earth Planet Sci Lett 482:342-356. https://doi.org/10.1016/j. epsl.2017.10.062

Tsukada S, Odaka T, Ashiya K, Ohtake K, Nozaka D (2004) Analysis of the envelope waveform of the initial part of P-waves and its application to quickly estimating the epicentral distance and magnitude. Zisin 56:351-361. https://doi.org/10.4294/zisin1948.56.4_351

Ueda H, Fujita E, Ukawa M, Yamamoto E, Irwan M, Kimata F (2005) Magma intrusion and discharge process at the initial stage of the 2000 activity of Miyakejima, Central Japan, inferred from tilt and GPS data. Geophy J Int 61(3):891-906. https://doi.org/10.1111/j.1365-246X.2005.02602.x

Ueda H, Kozono T, Fujita E, Kohno Y, Nagai M, Miyagi Y, Tanada T (2013) Crustal deformation associated with the 2011 Shinmoe-dake eruption as observed by tiltmeters and GPS. Earth Planets Space 65:6. https://doi. org/10.5047/eps.2013.05.001

Uehira K, Kanazawa T, Mochizuki M, Fujimoto H, Noguchi S, Shinbo T, Shiomi K, Kunugi T, Aoi S, Matsumoto T, Sekiguchi S, Okada Y, Shinohara M, Yamada T (2016) Outline of seafloor observation network for earthquakes and tsunamis along the Japan Trench (S-net) EGU General Assembly 2016, EGU2016-13832

Ueno T, Saito T, Shiomi K, Haryu Y (2015) Monitoring the instrument response of the high-sensitivity seismograph network in Japan (Hi-net): effects of response changes on seismic interferometry analysis. Earth Planets Space 67:135. https://doi.org/10.1186/s40623-015-0305-0

Urabe T, Tsukada S (1992) WIN -A workstation program for processing waveform data for microearthquake networks. Programme and Abstracts, The Seismological Society of Japan, 1992 Fall Meeting 2:41 (in Japanese)

Utsu T (1961) A statistical study on the occurrence of aftershocks. Geophys Mag 30:521-605

Waldhauser F, Ellsworth WL (2000) A double-difference earthquake location algorithm: method and application to the northern Hayward fault. Bull Seismol Soc Am 90:1353-1368. https://doi.org/10.1785/0120000006

Wallace LM, Araki E, Saffer D, Wang X, Roesner A, Kopf A, Nakanishi A, Power W, Kobayashi R, Kinoshita C, Toczko S, Kimura T, Machida Y, Carr S (2016) Near-field observations of an offshore Mw 6.0 earthquake from an integrated seafloor and subseafloor monitoring network at the Nankai Trough, southwest Japan. J Geophys Res Solid Earth 121:8338-8351. https://doi.org/10.1002/2016JB013417

Watanabe $H$ (1971) Determination of earthquake magnitude at regional distance in and near Japan. Zisin 24:189-200. https://doi.org/10.4294/ zisin1948.24.3_189 (in Japanese with English abstract)

Wessel P, Smith WHF (1998) New, improved version of Generic Mapping Tools released. EOS Trans Am Geophys Un 79:579

Wieland E, Streckeisen G (1982) The leaf-spring seismometer: design and performance. Bull Seismol Soc Am 72:2349-2367

Yamada M, Kumagai H, Matsushi Y, Matsuzawa T (2013) Dynamic landslide processes revealed by broadband seismic records. Geophys Res Lett 40:2998-3002. https://doi.org/10.1002/grl.50437

Yamamoto E, Kumagai T, Shimada S, Fukuyama E (1988) Crustal tilt movements associated with the 1986-1987 volcanic activities of Izu-Oshima volcano-results of continuous crustal tilt observation at Gojinka and Habu. Kazan 33:S170-S178. https://doi.org/10.18940/kazanc.33. SPCL S170

Yamamoto S, Murono Y, Iwata N, Sakai K, Aoi S, Nakamura H, Suzuki W (2020) Real-time estimation of earthquake damage on railway. In: Proc 17th World Conf Earthq Eng, No C001702. (in press)

Yano TE, Matsubara M (2017) Effect of newly refined hypocenter locations on the seismic activity recorded during the 2016 Kumamoto Earthquake sequence. Earth Planets Space 69:74. https://doi.org/10.1186/s4062 3-017-0656-9

Yano TE, Takeda T, Matsubara M, Shiomi K (2017) Japan Unified hlgh-resolution relocated catalog for earthquakes (JUICE): crustal seismicity beneath the Japanese Islands. Tectonophysics 702:19-28. https://doi. org/10.1016/j.tecto.2017.02.017

\section{Publisher's Note}

Springer Nature remains neutral with regard to jurisdictional claims in published maps and institutional affiliations. 